\title{
Shift Safety Officer Falls through Hole in Floor into Basement of Vacant Row House and Dies from Smoke Inhalation - Maryland
}

\section{Executive Summary}

On November 12, 2014, a 62-year-old male career lieutenant, serving as the shift safety officer, died after falling through a hole in the floor of a vacant row house. At approximately 0019 hours, the career fire department was dispatched to a report of smoke in a vacant row house. Fire fighters began arriving on scene starting at 0022 hours and encountered a fire on the rear stairway that extended up the stairwell to the second floor. Battalion Chief 2 arrived on-scene at 0024 hours and assumed Incident Command. He quickly upgraded the dispatch to a working fire dispatch which sent additional engine and truck companies, an additional battalion chief, and the shift safety officer. The fire was quickly brought under control and the Incident Commander began releasing companies around 0046 hours. Remaining crews used ventilation fans to clear smoke from the fire structure and the vacant row house on side Delta. Crews working inside the Delta exposure observed that the ground-level floor at the rear of the structure had been completely removed but did not report this hazard to Incident Command when they exited. The shift safety officer entered the Delta exposure alone and apparently fell through the hole, receiving face and head injuries. All remaining personnel cleared the incident scene by 0223 hours. The fire department dispatch center

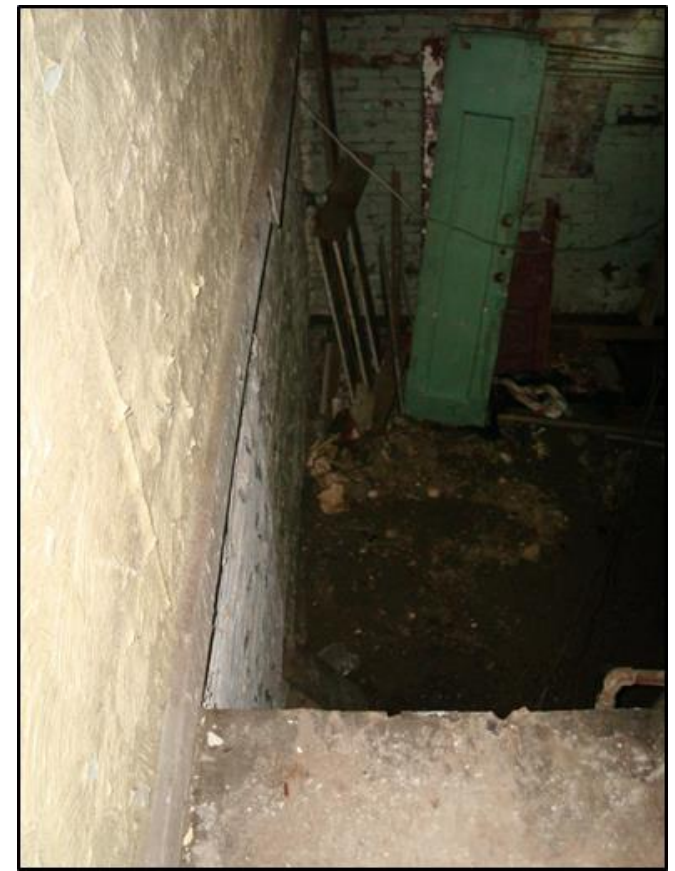

Hole in floor at rear of vacant row house. The victim fell approximately 7 feet onto the basement floor. (Photo NIOSH) began receiving phone calls reporting the shift safety officer's unattended vehicle blocking traffic around 0647 hours. Fire department resources were dispatched at 0748 hours to investigate the unattended vehicle. The shift safety officer was discovered in the basement of the Delta exposure at 0824 hours and was pronounced dead at the scene. The cause of death was determined to be smoke inhalation.

\section{Contributing Factors}

- Floor system at rear of the Delta exposure completely removed prior to incident

- Hole in floor (fireground hazard) not reported to the incident commander

- Smoke accumulation in the unventilated basement of the Delta exposure

- Ventilation in the Delta exposure was not completed

- Shift safety officer entered Delta exposure alone 


\section{Shift Safety Officer Falls through Hole in Floor into Basement of Vacant Row House and Dies from Smoke Inhalation - Maryland}

- Fireground accountability was ineffective

- Crew integrity was not maintained and single unit resources operated alone

- Fire Communications Bureau placed shift safety officer in service without verbal confirmation of his location.

\section{Key Recommendations}

- Fire departments should utilize a functional personal accountability system requiring a checkin and check-out procedure with the designated accountability officer or the incident commander

- Fire departments should ensure that the incident commander accounts for all resources before dissolving command

- Fire departments should train fire fighters on the principles of situational awareness

- Fire departments should train and empower all fire fighters to report unsafe conditions to Incident Command

- Fire departments should train all fire fighters and officers to report when tasks are completed or cannot be completed to their officer or the incident commander

- Fire departments should ensure that every fire fighter on the fire ground utilizes a Personal Alert Safety System (PASS) device including the ability to provide PASS devices for personnel operating in a potentially dangerous environment not requiring the use of self-contained breathing apparatus

- Fire departments should provide Battalion Chiefs and Chief Officers with a staff assistant or chief's aide to help manage information and communication

- Fire departments should ensure that single resource units (e.g. safety officers, fire investigators, etc.) do not function alone in IDLH environments at emergency scenes

- Fire departments should ensure that dispatch centers forward all reports of suspicious or unusual events to the appropriate authorities in a timely manner

- Fire departments should ensure that Mayday training program(s) are developed and implemented so that they adequately prepare fire fighters to call a Mayday.

The National Institute for Occupational Safety and Health (NIOSH), an institute within the Centers for Disease Control and Prevention (CDC), is the federal agency responsible for conducting research and making recommendations for the prevention of work-related injury and illness. In 1998, Congress appropriated funds to NIOSH to conduct a fire fighter initiative that resulted in the NIOSH "Fire Fighter Fatality Investigation and Prevention Program" which examines line-of-duty-deaths or on duty deaths of fire fighters to assist fire departments, fire fighters, the fire service and others to prevent similar fire fighter deaths in the future. The agency does not enforce compliance with State or Federal occupational safety and health standards and does not determine fault or assign blame. Participation of fire departments and individuals in NIOSH investigations is voluntary. Under its program, NIOSH investigators interview persons with knowledge of the incident who agree to be interviewed and review available records to develop a description of the conditions and circumstances leading to the death(s). Interviewees are not asked to sign sworn statements and interviews are not recorded. The agency's reports do not name the victim, the fire department or those interviewed. The NIOSH report's summary of the conditions and circumstances surrounding the fatality is intended to provide context to the agency's recommendations and is not intended to be definitive for purposes of determining any claim or benefit.

For further information, visit the program website at www.cdc.gov/niosh/fire or call toll free 1-800-CDC-INFO (1800-232-4636). 


\section{Death in the line of duty...}

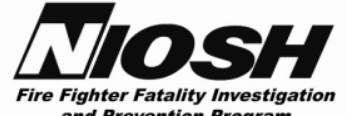

and Prevention Program

A summary of a NIOSH fire fighter fatality investigation

September 21, 2015

\section{Shift Safety Officer Falls through Hole in Floor into Basement of Vacant Row House and Dies from Smoke Inhalation - Maryland}

\section{Introduction}

On November 12, 2014, a 62-year-old male career lieutenant, serving as the shift safety officer, died after falling through a hole in the floor of a vacant row house. The shift safety officer fell into the basement, suffered minor face and head injuries, and died from smoke inhalation. On November 13, 2014, the U.S. Fire Administration notified the National Institute for Occupational Safety and Health (NIOSH) of this incident. The fire department also contacted NIOSH and requested NIOSH's assistance in conducting an investigation of the incident. At the request of the fire department, the NIOSH investigation was initiated on December 8, 2014. A safety engineer and an investigator from the NIOSH Fire Fighter Fatality Investigation and Prevention Program traveled to Maryland and met with the Fire Chief, the Assistant Fire Chief, members of the fire department's Safety and Health Office, and the department's Investigation Review Board. The NIOSH investigators traveled to the incident site to obtain photographs and measurements. They inspected the personal protective clothing and equipment worn by the victim. The NIOSH investigators traveled to the fire department's training academy to discuss training requirements and obtain training records and also visited the fire department's air mask maintenance shop. The NIOSH investigators interviewed fire fighters and fire officers who were involved in the November 12 incident. The NIOSH investigators also met with a representative of the Maryland Department of Labor, Licensing and Regulation (DLLR), Occupational Safety and Health (MOSH) who was investigating the incident.

At the request of the fire department, the NIOSH investigators arranged for representatives from the National Institute of Standards and Technology (NIST), Building and Fire Research Division, to conduct airflow velocity and pressure measurements at the incident site on December 11, 2014 to evaluate the use of the ventilation fans that had been deployed during the incident.

\section{Fire Department}

This career fire department serves an estimated population of 622,104 in an area covering 80.8 square miles and 11.3 square miles of water over a total area of 92.1 square miles.

The fire department has over 1,700 members who are divided into three management branches Emergency Operations, Safety and Member Services, and Community Risk Reduction. On average the department responds to more than 235,000 calls for service per year.

The Assistant Chief of Operations oversees the work of four (4) shift commanders and the emergency medical services (EMS) deputy chief. Operations personnel work out of 38 neighborhood fire stations. These stations house approximately 100 firefighting, emergency medical, and special operations companies. These units include 31 engine companies, 17 truck companies, 24 first-line advanced life support medic units, 3 peak time and 9 critical alert transport units, 4 squad companies (similar to a rescue engine) and a heavy rescue unit. Specialty units include hazmat trucks, special rescue vehicles, 


\section{Shift Safety Officer Falls through Hole in Floor into Basement of Vacant Row House and Dies from Smoke Inhalation - Maryland}

mobile command vehicles and fire boats. The department operates six emergency operations battalions and one EMS battalion, on four shifts. The work schedule for suppression is comprised of one 24 hour shift on, 24 hours off, 24 hours on followed by 5 days off. Once every 4 weeks members work an impact shift (24 hours). The work schedule for EMS is comprised of two 10 hour days, two 14 hour nights followed by 4 days off. Minimum staffing for engines, trucks, squads and the heavy rescue is four personnel per unit and a total of 292 members per shift.

A first-alarm assignment for a structure fire includes the dispatch of the five closest engine/squad companies, the two closest truck companies, the closest medic unit and the two closest battalion chiefs. The heavy rescue will also respond in a predetermined area of the city. Utilizing predetermined tactical assignments outlined in written standard operating procedures (SOPs), the first engine/squad will secure a continuous water supply and reports to the front (side Alpha), of the reported address. The second engine/squad will cover the water supply of the first engine/squad. The third engine/squad will assume the role of rapid intervention team (RIT) upon their arrival. The fourth engine/squad will secure a continuous water supply and report to the rear (side Charlie), of the reported address. The fifth engine/squad will cover the water supply of the fourth engine/squad. The first truck reports to side Alpha and the second to side Charlie. Assignments may be altered by responding units via the fire ground radio channel. A working fire assignment will dispatch the next closest engine or squad company, the next closest truck company, the closest AIRFLEX unit, the on-duty shift safety officer and the shift commander. A second alarm assignment will add the next three closest engine/squad companies, the next closest truck company, the heavy rescue, if it is not already on the incident, the next closest battalion chief, the next closest medic unit, the on duty fire investigator and the closest EMS District Supervisor. Additional alarms are the next four closest engines/squads and the next two closest trucks. As alarms increase, staff officers and specialty units are also added.

Battalion chiefs have all been trained as Incident Safety Officers (ISO). Two suppression battalion chiefs are dispatched on a first alarm assignment. The second dispatched battalion chief serves as the Incident Safety Officer until relieved by the shift safety officer. Captains who act as battalion chiefs will also have the same responsibilities even though they may not yet have been fully trained as an ISO. Chief officers at the shift commander rank and above are assigned chief aides who perform administrative duties, drive the chief officer's vehicle, and assist on the fire ground with communications and accountability as necessary. Battalion chiefs are not assigned aides.

The city is divided into predetermined "Box Areas" which are geographic areas within a station's first due territory and are numbered using the engine in the station's number as a prefix. For example, the station of engine 8 has box areas 8-1, 8-2, etc. Station order to the box areas have been recorded into the Computer Aided Dispatching system, to allow dispatchers the ability to send the closest units more efficiently.

The Assistant Chief of Safety and Member Services oversees the Fire Department Human Resources, Safety Division, Education and Training Academy, Fiscal Office, and the Office of Legal Counsel. 


\section{Shift Safety Officer Falls through Hole in Floor into Basement of Vacant Row House and Dies from Smoke Inhalation - Maryland}

\section{Safety Division}

The fire department Safety and Health Office is an independent function within fire department headquarters. The Assistant Chief of Safety and Member Services manages the operations of the Safety Division. At the time of this incident, three safety officers were assigned to the Safety and Health Office, each working 40 hours per week. In addition, each of the four operational shifts had an assigned shift safety officer, working the 24-hour shift rotation. The lieutenant who died in this incident was the A-shift safety officer. Note: B-Shift was on duty at the time of the incident. The lieutenant was assigned to A-Shift and was working his monthly impact shift on B-Shift at the time of the fire.

Each operational shift has a number of lieutenants trained to fill-in as the shift safety officer when necessary. Requirements to be a shift safety officer include achieving the rank of lieutenant, attending the 2-day Incident Safety Officer (ISO) course through the U.S. Fire Administration National Fire Academy, and hands-on training that includes riding with a shift safety officer until deemed to be adequately qualified.

The duties of the shift safety officer include assisting the Chief of Safety in maintaining the function of the Safety and Health Office, line-of-duty injury investigation and reporting, fire department vehicle accident investigation, and serving as the Incident Safety Officer (ISO) at hazardous materials incidents, technical rescues and fireground operations. The shift safety officer responds to emergency incidents that involve a high risk to fire department personnel including:

- Working Fires

- Full Rescue Assignments

- Mass Casualty Incidents

- Hazmat Task Force Response

- Dive/Rescue Team / Water Rescue

- Special Rescue Operation Team

- Cave-in / Confined Space

The shift safety officer is dispatched on a working fire but can self-dispatch any time it is deemed necessary. The Chief of Safety is dispatched on all third-alarm fires.

Once the shift safety officer is dispatched and arrives at the scene of a working fire, the shift safety officer dons the necessary personal protective clothing and equipment, including a portable radio, and reports to the incident commander for a face-to-face conference. After receiving a briefing and any assignments specific to the incident, the shift safety officer performs a 360-degree size-up of the incident scene, looking for specific safety hazards. The shift safety officer also meets with the acting incident safety officer (the second-due battalion chief) and assumes the role of ISO. The shift safety officer would then brief the incident commander on any obvious hazards present, and then go to the area of most activity. The shift safety officer wears an orange fire helmet for visibility and easy identification. The shift safety officer has the authority to alter, suspend or terminate any unsafe act or operation. The shift safety officer may also serve as a liaison with other agencies that respond to fires 


\section{Shift Safety Officer Falls through Hole in Floor into Basement of Vacant Row House and Dies from Smoke Inhalation - Maryland}

or emergencies in matters that pertain to safety. Examples of the specific duties and types of hazards the ISO would look for include: walking the fireground and establish a fireground perimeter; surveying incidents and personnel for the following:

- Proper donning and use of protective clothing and safety gear

- Fatigued personnel (heat and cold related problems)

- Structural conditions (roof, walls, floors, windows, etc.)

- Utilities (overhead wires, gas lines, liquid propane (LP) gas tanks, etc.)

- Safe apparatus placement (outside of potential collapse zone, properly secured, wheel chocks).

- Ladders (footing, placement)

- Operations (opposing hose lines, use of portable master streams, proper equipment use)

- Rapid intervention team placement

- Adequate lighting

- Safe operating procedures.

The ISO is responsible for reporting unsafe acts and corrective actions to the incident commander and working with the incident commander to ensure personnel on the incident are aware of any special circumstances or dangers.

The Assistant Chief of Community Risk Reduction oversees three support divisions which are the Office of the Fire Marshal, Information Technology Services, and Logistics. All of these divisions help in supporting the operational functions of the fire department. The Office of the Fire Marshal provides public fire safety and educational resources. Logistics is responsible for the procurement of all fire department apparatus, equipment, and supplies while overseeing the maintenance of all facilities. Information technology helps to support the fire department's internal communications infrastructure and fire dispatch system.

\section{Training and Experience}

The fire department maintains a Division of Education and Training to help ensure that each member of the fire department receives the appropriate instructions and information needed to properly perform duties and prepare for advancement. The Division of Education and Training designs, develops and provides programs for probationary training, company level training, battalion level training, officer candidate training, continuing education training and special training (hazmat, technical rescues, etc.).

The city fire department recruits fire fighters through a civil service examination process. After passing the civil service examination, potential candidates are placed on hiring list. Potential candidates must complete a candidate physical ability test (CPAT). Candidates are assigned to a recruit class. The fire department operates a training academy where recruits attend a 6-month nonresident academy. Recruits do not reside at the academy during the 6-month training class. The recruit class covers Emergency Medical Technician (EMT) Basic, Fire Fighter I, Fire Fighter II, Hazmat Operations, Vehicle Operator and fire department-specific skills classes covering subjects such as self-contained breathing apparatus (SCBA) and personal protective equipment (PPE) training, ladder training, interior fire fighting, and other subjects. Recruits receive ProBoard certification for 


\section{Shift Safety Officer Falls through Hole in Floor into Basement of Vacant Row House and Dies from Smoke Inhalation - Maryland}

Firefighter I, Firefighter II, Hazmat Awareness and Hazmat Operations through the Maryland Fire and Rescue Institute (MFRI).

Graduates from the 6-month recruit class are assigned to a company. Each battalion has specific training requirements that address the battalion's unique geographical needs. Recruits assigned to a company wear a yellow helmet and are assigned a training manual booklet with specific tasks that must be checked off by the recruit's supervisor. Once all tasks are completed and checked off, the recruit gets a black helmet.

In addition, each fire fighter must complete 16 hours of company level training per month. Fire fighters can also take outside training classes at their own expense. Every fire fighter receives live fire training once each year. Two engine companies and one ladder company are sent to the fire academy for live fire training where they drill on various training scenarios. Each fire fighter also receives annual training in rapid-intervention-team (RIT) operations.

Fire fighters with 1 year of experience can test for pump operator (PO) and emergency vehicle driver (EVD) certification. Fire fighters with a minimum of 3 years of experience can test for the lieutenant position. Lieutenants with at least one year of experience as a lieutenant can test for the captain position. The fire department maintains pre-requisite training and experience requirements for each level of rank. Since 2011, the fire department has provided funding for fire fighters to receive ProBoard certification.

The incident commander at this incident had over 16 years of experience as a fire fighter and held the rank of Battalion Chief since 2010. He had been a fire officer with the department since being promoted to lieutenant in 2002. The fire department's training records showed that he had completed training in subjects including: Responder to Hazardous Materials/WMD Incident - Awareness; Responder to Hazardous Materials/WMD Incidents - Operational; Fire Fighter I; Fire Fighter II, Emergency Medical Technician, Basic; Vehicle \& Machinery Technical Rescuer I \& II; Fire Service Instructor I; Fire Service Instructor II; Fire Service Instructor III; Health \& Safety Officer; and others.

The shift safety officer who died in this incident had over 40 years of experience as a fire fighter and held the rank of lieutenant since 2004. He had worked in the Safety Office for the past 10 years and was the senior shift safety officer. The fire department's training records showed that he had completed training in subjects including: Hazardous Materials/WMD Incident - Awareness; Hazardous Materials Operations; Responder to Hazardous Materials/WMD Incidents - Operational; Hazardous Materials: Recognizing and Identifying; Self-contained Breathing apparatus (SCBA) Training; Protective Envelope Foam Training; Fire Investigator; Fire/Arson Investigation; IS-00100.a Introduction to the Incident Command System (ICS-100); IS-00200.a ICS for Single Resources and Initial Action Incidents (ICS-200); IS-00700.a National Incident Management System (NIMS) - An Introduction (ICS 700); IS-00800.b National Response Framework, An Introduction (ICS-800); EMS Basic Life Support Skills Training; EMS Advanced Life Support Skills Training; Fire Suppression Skills Training; City Driver Permit Training; Fire Department Driver Training; 2-Minute Drill 


\section{Shift Safety Officer Falls through Hole in Floor into Basement of Vacant Row House and Dies from Smoke Inhalation - Maryland}

(donning personal protective clothing and SCBA); Maze Training; Lead Off (supply hose and hydrant connection); One-man Ladder Carry; Two-man Ladder Carry; Charged Hoseline; and several others.

\section{Equipment and Personnel}

The fire department follows established procedures for responding to emergency calls dispatched by the Fire Communications Bureau (fire dispatch or FCB) based upon the size and nature of the incident reported. Assignments are made based upon defined response protocols for each alarm level. Table One lists the different alarm types and defined assignments. Both the Fire Communication Bureau (FCB) and the incident commander have the flexibility to modify the alarm assignments when necessary.

\section{Table One - Alarm Types and Assignments}

\begin{tabular}{|c|c|c|}
\hline Alarm Type & Alarm Level & Units Assigned \\
\hline Silent Alarm & $1^{\text {st }}$ Alarm & 1 engine or 1 truck or both as dictated by incident \\
\hline Tactical Box Alarm & $1^{\text {st }}$ Alarm & 2 engines, 1 truck \\
\hline $\begin{array}{l}\text { Task Force Box } \\
\text { Alarm }\end{array}$ & $1^{\text {st }}$ Alarm & 3 engines, 1 truck, 1 Battalion Chief \\
\hline Box Alarm & $1^{\text {st }}$ Alarm & $\begin{array}{l}5 \text { engines, } 2 \text { trucks, } 2 \text { Battalion Chiefs, Rescue 1(if } \\
\text { near downtown, } 1 \text { Medic Unit, Fireboats (if near } \\
\text { waterfront), } 3^{\text {rd }} \text { due engine is designated RIT. }\end{array}$ \\
\hline Working Fire & $1^{\text {st }}$ Alarm Upgrade & $\begin{array}{l}1 \text { engine, } 1 \text { truck, Shift Commander, Shift Safety } \\
\text { Officer, } 1 \text { AirFlex unit. }\end{array}$ \\
\hline $2^{\text {nd }}$ Alarm & $2^{\text {nd }}$ Alarm Assignment & $\begin{array}{l}4 \text { engines, } 2 \text { truck, } 1 \text { EMS Officer, } 1 \text { Medic Unit, } 1 \\
\text { Battalion Chief, } 1 \text { Fire Investigation Bureau } \\
\text { officer }\end{array}$ \\
\hline $3^{\text {rd }}$ Alarm & $3^{\text {rd }}$ Alarm Assignment & $\begin{array}{l}4 \text { engines, } 2 \text { trucks, Mobile Command Unit, EMS } \\
\text { Battalion Chief }\end{array}$ \\
\hline $4^{\text {th }}$ Alarm & $4^{\text {th }}$ Alarm Assignment & 4 engines, 2 trucks \\
\hline $5^{\text {th }}$ Alarm and up & $5^{\text {th }}$ Alarm Assignment & 4 engines, 2 trucks \\
\hline
\end{tabular}




\section{Shift Safety Officer Falls through Hole in Floor into Basement of Vacant Row House and Dies from Smoke Inhalation - Maryland}

This incident initially involved a dispatch for a report of smoke in a row house. Per established fire department procedures, the following equipment and personnel were dispatched for a box alarm assignment:

\section{Box Alarm}

Engine 31:

Engine 6:

Engine 13:

(E31; Acting Lieutenant, pump operator, 2 fire fighters)

(E6; Lieutenant, pump operator, 2 fire fighters)

(E13; Acting Lieutenant, pump operator, 2 fire fighters - per procedures, assigned as the RIT)

Engine 33:

(E33; Lieutenant, pump operator, 2 fire fighters)

Engine 23:

(E23; Lieutenant, pump operator, 2 fire fighters)

Truck 5:

(T5; Lieutenant, 2 emergency vehicle drivers, fire fighter)

Truck 1:

(T1; Acting Lieutenant, emergency vehicle driver, 2 fire fighters)

Medic 16:

(M16; ambulance unit with 2 paramedics)

Battalion Chief 2: $\quad$ (BC 2-Incident Commander)

Battalion Chief 6: $\quad$ (BC 6)

The fire department maintains two support vehicles, called AIRFLEX units that carry extra SCBA air cylinders, portable lights, compressed-air foam and other support items. AirFlex units are normally dispatched on a working fire alarm but in this incident, AirFlex 2 was dispatched on request of the incident commander prior to requesting the working fire alarm. Shortly after arriving on-scene, and after confirming that smoke was showing, the incident commander (BC2) radioed dispatch to request an AirFlex unit and shortly after that, upgraded the incident to a working fire.

Per fire department procedures, the following additional units were dispatched for the working fire alarm.

\section{Working Fire Alarm}

Engine 8:

Truck 16:

Safety Officer 2:

Shift Commander:

Fire Investigation Unit:
(E8; Lieutenant, pump operator, 2 fire fighters)

(T16: Lieutenant, 2 emergency vehicle drivers, fire fighter)

(Shift safety officer (the victim) )

(Car 5: Acting Deputy Chief and chief's aide-Acting Shift commander)

(Captain - arson investigator)

\section{Structure}

This incident occurred in two adjoining vacant row houses. The row houses were located near the middle of a city block containing 12 row houses sharing common side walls that were constructed in the 1920 era. This type of construction is common throughout the city and the regional area. A row house is a style of medium-density urban housing that originated in Europe in the $16^{\text {th }}$ century, where a row of identical or mirror-image houses share common side walls. 1

The exterior walls and common side walls were brick and mortar construction. The fire occurred in the fifth house from the western end of the block. Most of the row houses in the block were vacant. 


\section{Shift Safety Officer Falls through Hole in Floor into Basement of Vacant Row House and Dies from Smoke Inhalation - Maryland}

The side Bravo exposure was occupied. The fire structure was vacant and boarded up and was commonly used for drug and other illegal activities. The side Delta exposure where this fatality occurred was also vacant and boarded up. In this particular block of row houses, the common side walls were constructed of brick but did not extend into the attic void space. The structure included a flat roof covered with multiple layers of asphalt paper and shingles. Electrical and gas utilities were shut off to both row houses.

The row houses measured approximately 14 feet 2 inches wide by 55 feet long. Each row house had three stories above ground and a full basement partially below grade. Two small basement windows were located at street level in the front of each row house (see Photo 1 (entire block) and Photo 2 (close-up of basement windows)). The structure was located to the north of a major city street running east and west with two lanes of traffic in each direction plus a parking lane on the north side of the street.

Photo 3 shows the orientation of the fire structure in the middle of the row. The shift safety officer was found in the Delta exposure. At some point, the side Delta exposure had undergone some refurbishment work. The complete floor system had been partially removed at the rear of the first (ground level) floor. All the floor boards and floor joists had been removed between the two common side walls, leaving a hole approximately 13 feet wide and 7 feet long at the rear of the structure (see Photo 4). The hole was located just past the basement steps. A hallway located on side Bravo led from the front room to the rear (side Charlie). 
Shift Safety Officer Falls through Hole in Floor into Basement of Vacant Row House and Dies from Smoke Inhalation - Maryland

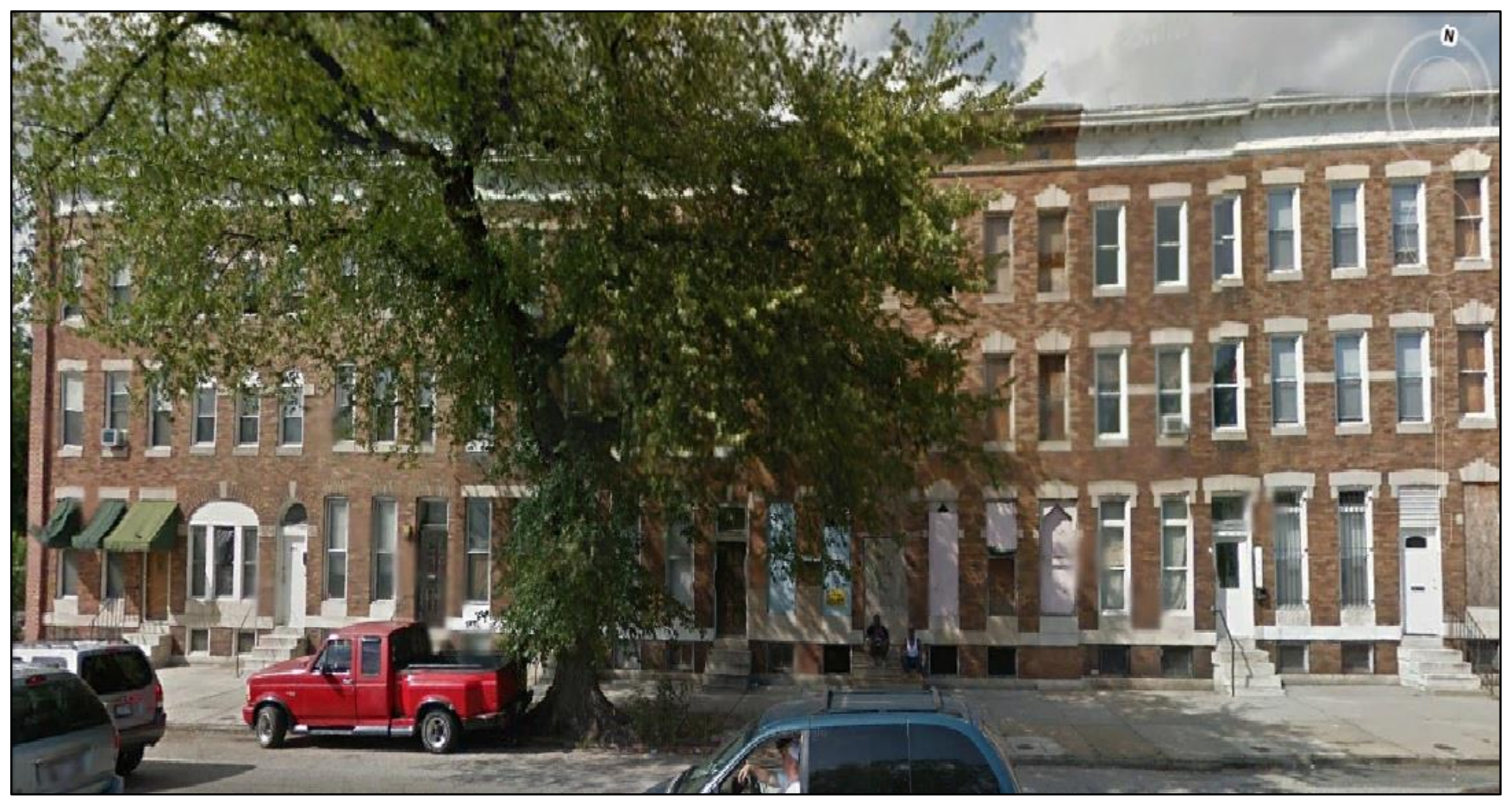

Photo 1. View of the city block were the incident occurred. Row houses fronting the entire city block are typical in this neighborhood.

(Photo adapted from Google Earth Street View. Imagery date: 9/2014) 
Shift Safety Officer Falls through Hole in Floor into Basement of Vacant Row House and Dies from Smoke Inhalation - Maryland

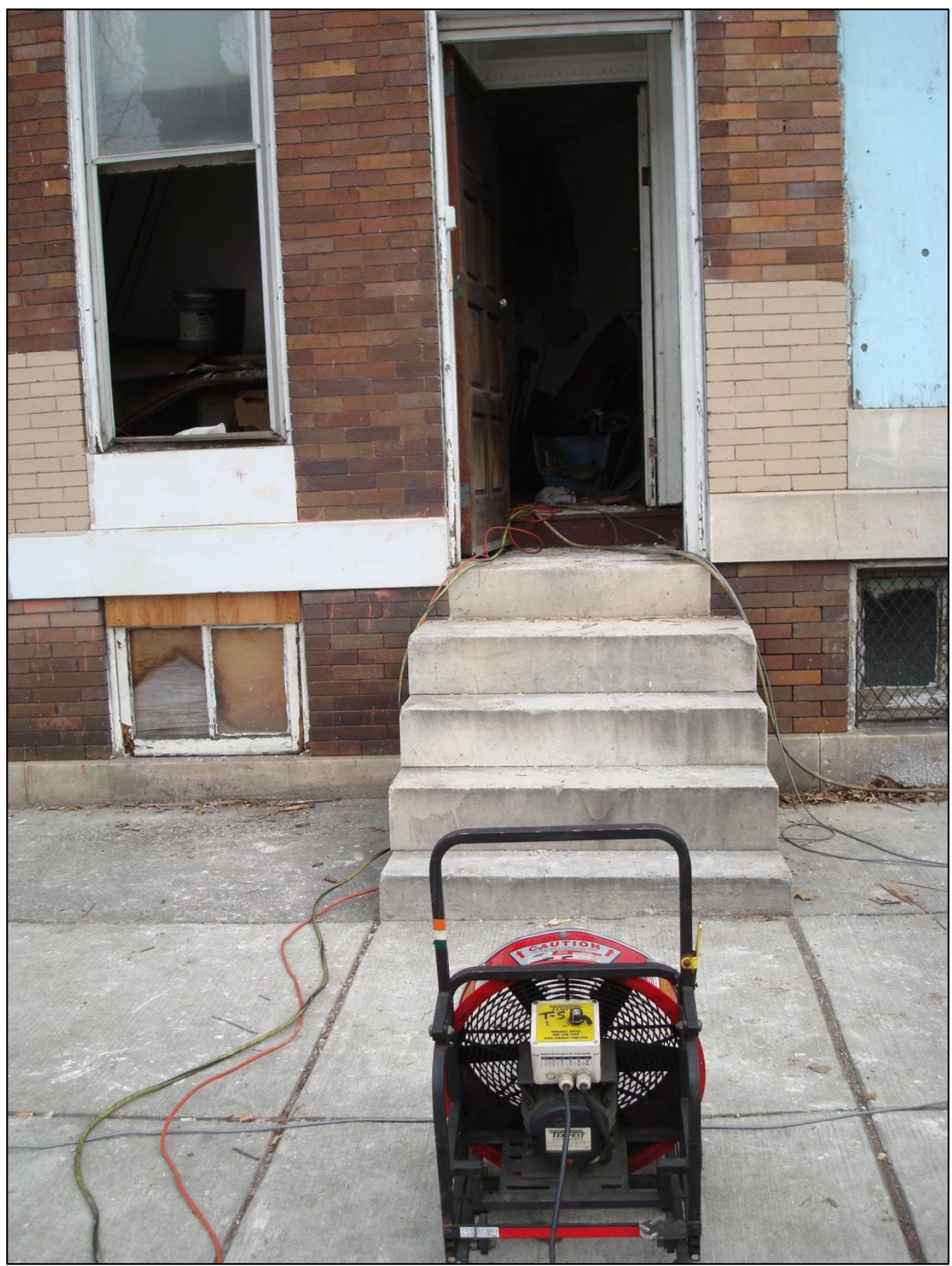

Photo 2. View of the front door to the Delta exposure building. Note the small basement windows on both sides of the steps. Also note that this photo was taken during post-incident flow path testing by NIST

(Photo NIOSH) 
Shift Safety Officer Falls through Hole in Floor into Basement of Vacant Row House and Dies from Smoke Inhalation - Maryland

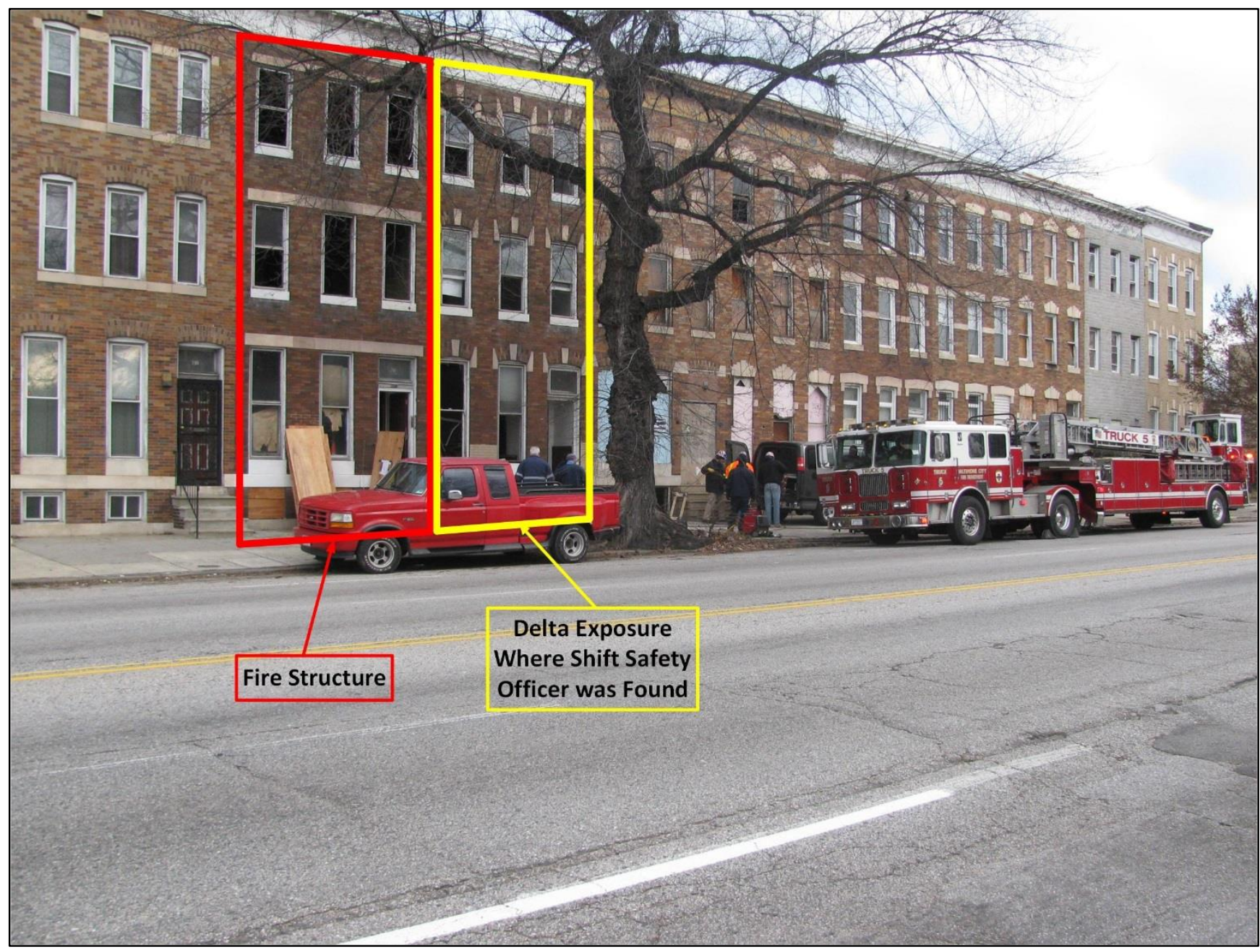

Photo 3. View of the row houses where incident occurred. The shift safety officer was found in the Delta exposure. The shift safety officer's fire department vehicle was parked to the left (to the west) just out of view. Row houses fronting the entire city block are typical in this neighborhood. Photo taken during the NIST pressure and ventilation testing on December 11, 2014

(Photo courtesy of Fire Department / Fire Investigation Bureau) 


\section{Shift Safety Officer Falls through Hole in Floor into Basement of Vacant Row House and Dies from Smoke Inhalation - Maryland}

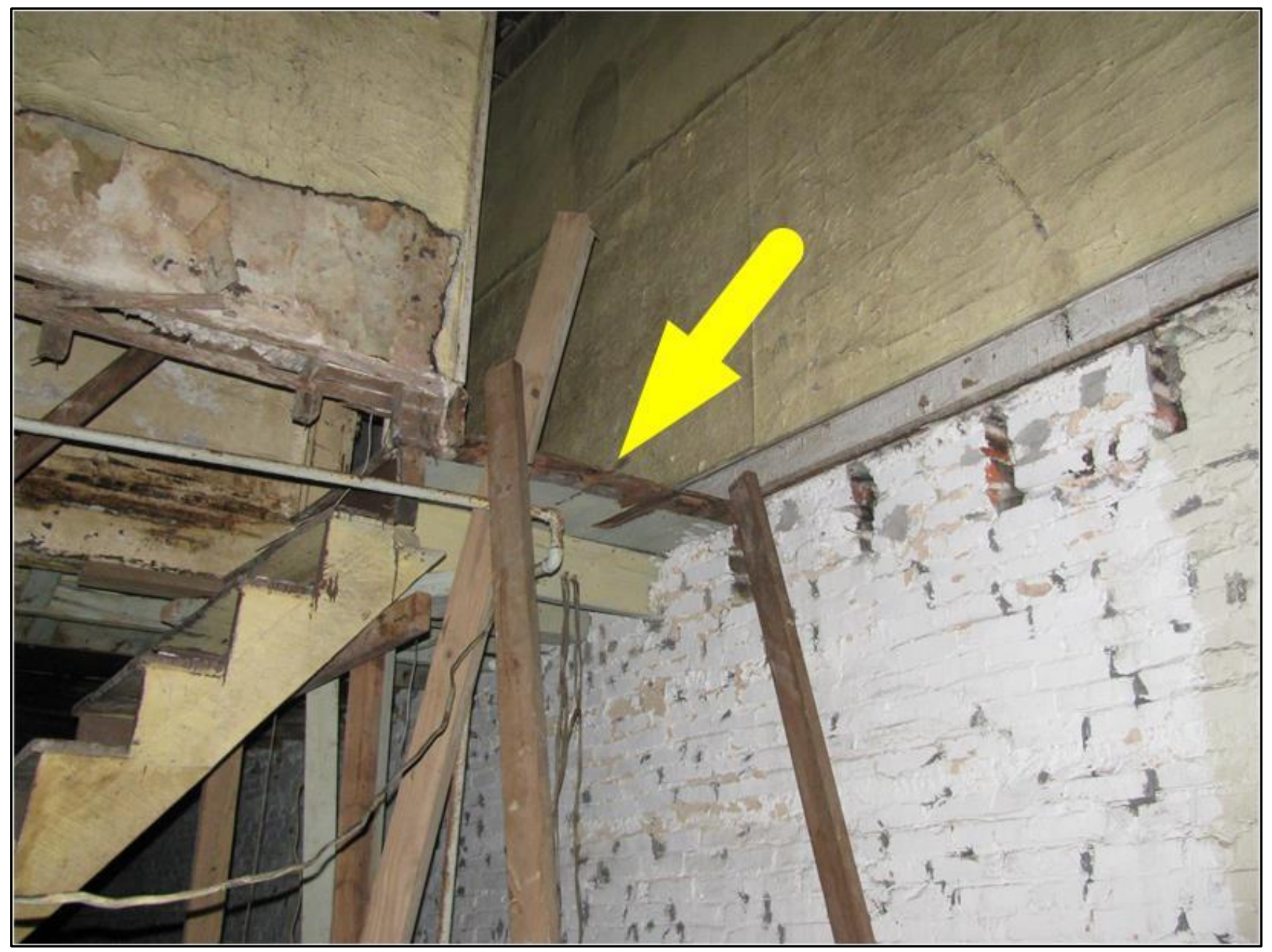

Photo 4. View of the missing floor taken from near the approximate location where the shift safety officer likely landed on the basement floor. It is believed he stepped off the first floor at the area highlighted by the arrow.

(Photo courtesy of Fire Department / Fire Investigation Bureau)

\section{Timeline}

Note: This timeline is provided to set out, to the extent possible, the sequence of events as the fire department responded. The times are approximate and were obtained from review of the dispatch audio records, witness interviews, photographs of the scene and other available information. In some cases the times may be rounded to the nearest minute, and some events may not have been included. The timeline is not intended, nor should it be used, as a formal record of events.

- 0019:08 Hours

911 Call to fire communications bureau (FCB or fire dispatch). 


\section{Shift Safety Officer Falls through Hole in Floor into Basement of Vacant} Row House and Dies from Smoke Inhalation - Maryland

- 0019:32 Hours

FCB initiates box alarm dispatch for a report of smoke in a structure (row house). Engine 31, Engine 6, Engine 13, Engine 33, Engine 23, Truck 5, Truck 1, Medic 16, Battalion Chief 2, Battalion Chief 6 were dispatched on the first alarm.

- 0020:16 - 0022:02 Hours

All units enroute. Engine 13 acknowledges they are RIT.

- 0022:10 Hours

Truck 5 radios on scene. Reports smoke showing and assumes command.

- 0022:19 Hours

FCB (fire dispatch) acknowledges Truck 5 is on scene and has command.

- 0022:24 Hours

Medic 16 on scene

- 0022:55 Hours

Engine 31 radios they have hydrant

- 0023:00 - 0024:00 Hours

Engine 6, Engine 13, Engine 33, Engine 23, and Truck 1 arrive on scene. Engine 13 is RIT.

- 0024:14 Hours

Battalion Chief 2 on scene and radios size up - "3 story brick, middle of the group, looks like we've got smoke showing $3^{\text {rd }}$ floor, alpha side. Units are initiating an interior attack. You can make Battalion Chief 2 command."

- 0026:31 Hours

AirFlex 2 support vehicle dispatched on the direction of the incident commander (BC 2).

- 0028:22 Hours

IC radios FCB and requests that incident be upgraded to a working fire.

- 0028:32 Hours

Engine 8, Truck 16, Car 5 and Shift Safety Officer dispatched.

- 0029:11 Hours

Battalion Chief 6 on scene and assumes safety officer duties (goes to side Charlie).

- 0030:53 Hours

Shift Safety Officer enroute. 


\section{Shift Safety Officer Falls through Hole in Floor into Basement of Vacant} Row House and Dies from Smoke Inhalation - Maryland

- 0032:17 Hours

IC radios Safety (BC 6) and asks for a report from side Charlie.

- 0032:48 Hours

BC 6 (Safety) radios IC and reports that side Charlie is opened up, all visible fire has been knocked down, just light smoke showing on the $2^{\text {nd }}$ floor.

- 0042:01 Hours

IC radios BC 6 to advise him that Shift Safety Officer will be Safety and BC 6 will be Charlie Division.

- 0042:09 Hours

BC 6 acknowledges transfer of assignments

- 0045:35 Hours

IC radios FCB and places fire under control. Soon after, working fire units in staging were put back into service.

- 0047:17 Hours

IC radios Truck 1 to open up Delta exposure. IC says he is sending in a company with hose line into the front just in case. The RIT crew (Engine 13) is sent in the front door of the Delta exposure to search for fire extension.

- 0047:30 Hours

Truck 1 acknowledges order to open up Delta exposure (rear).

- 0056:14 Hours

Shift Safety Officer radios to crew "second floor Delta"

- 0056:26 Hours

Engine 13 radios command and reports... "Right now we don't have any fire, just trapped smoke, we're opening up now checking it out."

- 0056:38 Hours

Shift Safety Officer radios "copy."

- 0057:14 Hours

IC radios Truck 5 to set up ventilation fans to clear out smoke from fire building and Delta exposure.

- 0057:21 Hours

Truck 5 radios "copy Chief”. 


\section{Shift Safety Officer Falls through Hole in Floor into Basement of Vacant} Row House and Dies from Smoke Inhalation - Maryland

- 0058:42 - 0058:48 Hours

Shift Safety Officer's radio was turned off then back on.

- 0104:00 Hours (approximate time)

Shift Safety Officer was observed talking to IC in street in front of row houses. (see Photo 5).

Note: Shortly after this photo was taken, the Shift Safety Officer entered the Delta exposure alone. Photo 5 represents his last documented location and time.

- 0152 Hours

Incident Commander (BC 2) radios the Fire Communications Bureau (FCB) and transfers command to Truck 5

- 0154 Hours

$\mathrm{BC} 2$ leaves fireground and returns to quarters

- 0203 - 0023 Hours

All remaining crews leave fireground and go back into service, except for the Shift Safety Officer.

- 0334 Hours

Fire Communications Bureau places the Shift Safety Officer in service without verification of his location.

- 0525 Hours

On-coming Shift Safety Officer reports for work and notices Safety Officer vehicle is not in quarters.

- 0647 Hours

FCB receives phone call from civilian reporting that fire department vehicle is parked in street facing the wrong way and blocking traffic lane (at scene of row house fire).

- 0650 Hours

On-coming Shift Safety Officer calls victim's cell phone with no answer.

- 0708 Hours

FCB receives another phone call from civilian reporting that fire department vehicle is parked in street.

- 0710 Hours

On-coming Shift Safety Officer calls victim's cell phone again with no answer 


\section{Shift Safety Officer Falls through Hole in Floor into Basement of Vacant Row House and Dies from Smoke Inhalation - Maryland}

- 0715 Hours

Deputy Chief receives the first of several calls from FCB concerning fire department vehicle parked in street blocking traffic lane.

\section{- 0748 Hours}

Engine company sent on administrative detail assignment to investigate fire department vehicle parked in street blocking traffic lane.

\section{- 0824 Hours}

Victim's body found in basement of Delta exposure.

- 0852 Hours

Victim pronounced dead at the scene by the EMS supervisor.

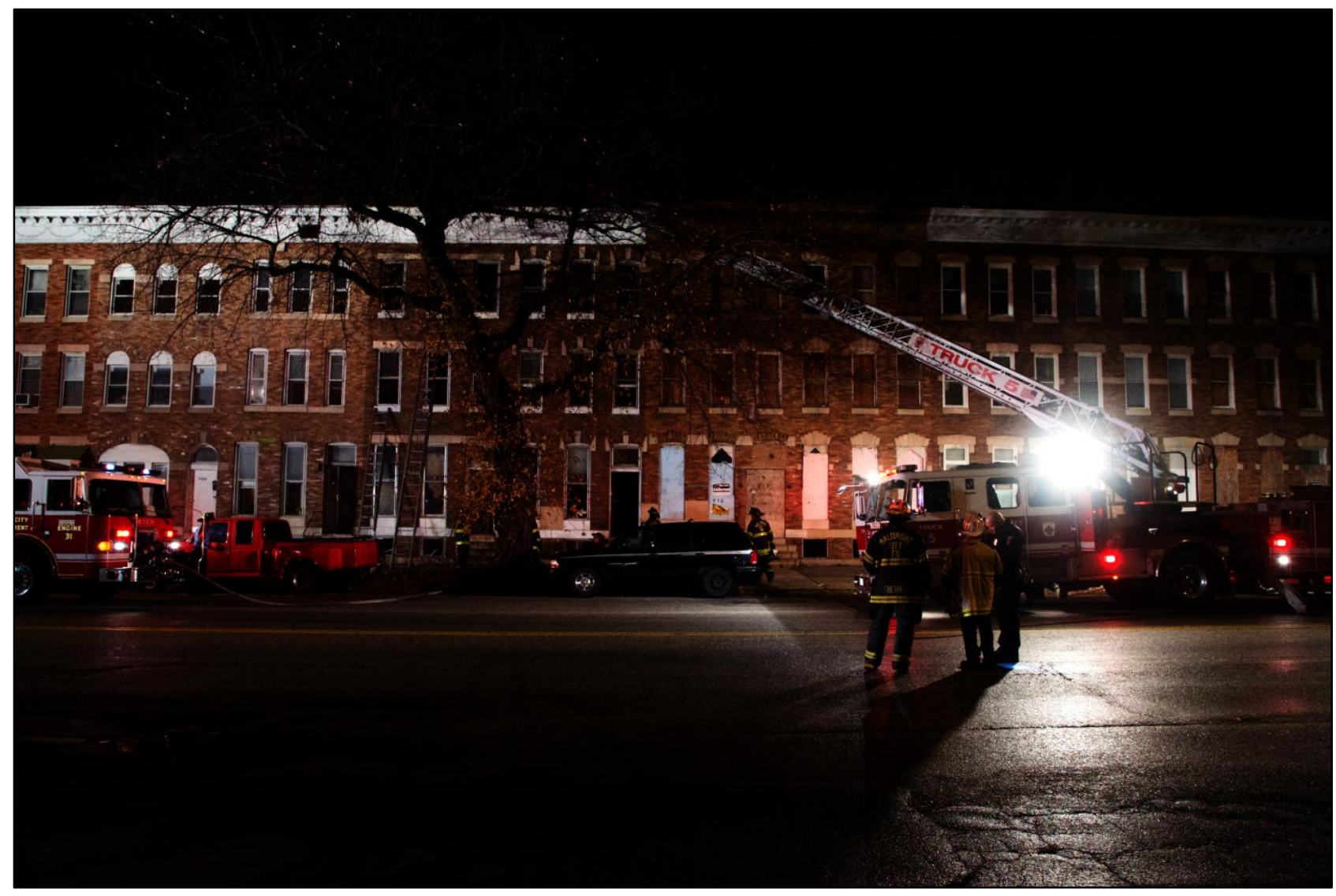

Photo 5. Photo taken at approximately 0104 hours showing shift safety officer in street with the incident commander and another fire fighter. Photo was taken shortly before the shift safety officer entered the Delta exposure alone.

(Photo courtesy of Fire Department) 


\section{Shift Safety Officer Falls through Hole in Floor into Basement of Vacant Row House and Dies from Smoke Inhalation - Maryland}

\section{Personal Protective Equipment}

At the time of the incident, the shift safety officer was wearing his station uniform, work boots, turnout coat and pants, gloves and fire helmet. He was not wearing a self-contained breathing apparatus. He was wearing his left glove and his right glove was found with his helmet. Police took possession of all personal protective equipment and clothing following the incident. He was carrying a personal light attached to his turnout coat. It could not be verified whether the light was turned on or off at the time he was found. He was carrying a fire department-issued radio designated as the shift safety officer's radio. The radio was turned on and the battery was charged at the time the shift safety officer was located. The radio was found in his coat pocket with the lapel microphone attached to the upper left side (lapel) of his turnout coat. He had used the radio at least two times prior to his last documented time on the fireground (at approximately 0104 hours (see Photo 5)). These transmissions were recorded on fireground channel A-16, the correct fireground channel for this incident. The radio was equipped with an emergency activation button which was not utilized during this incident.

At the request of the fire department, NIOSH took possession of the shift safety officer's radio and fire helmet. The NIOSH National Personal Protective Technology Laboratory (NPPTL) coordinated the evaluation and testing of both the radio and the fire helmet. Both the radio manufacturer and the helmet manufacturer provided assistance to NPPTL during the evaluation process.

\section{Radio Evaluation Summary}

The radio evaluation was conducted on January 6, 2015 under the direction of NIOSH NPPTL. As part of the evaluation process, the radio was first evaluated at one of the fire department's stations and then transferred to the manufacturer's testing facility for additional evaluation and testing. This evaluation consisted of testing the radio for proper programing and operation to determine if there were any faults in its operation that may have contributed to the fatality.

During this process, the radio operated properly. No faults or programming issues were noted during the inspection and evaluation that would have contributed to the fire fighter fatality.

Note: Prior to the NPPTL radio evaluation, the fire department evaluated the radio's performance by operating the radio from within the Delta exposure basement on December 11, 2014 during the NIST pressure and ventilation testing. Fire department personnel radioed the Fire Communication Bureau and received acknowledgement. At that time, the radio performed as expected.

\section{Helmet Evaluation Summary}

The helmet worn by the shift safety officer was less than one year old and in very good condition. NIOSH investigators observed a scuff mark and stress crack in the helmet's outer shell to the left of the helmet emblem. A quantity of what appeared to be dried blood was observed on the outer shell. The scuff mark and stress crack in the helmet suggest a glancing impact from the fall. The disposition of the suspension system is consistent with a directional force suffered during the fall. The interior impact cap showed no signs of damage from a direct or glancing impact. See Photo 6 and Appendix One for more information. 


\section{Shift Safety Officer Falls through Hole in Floor into Basement of Vacant Row House and Dies from Smoke Inhalation - Maryland}

The helmet involved in this incident, while structurally identical to the NFPA version of the helmet, only met the requirements of OSHA US-OSHA Standard 29 CFR 1910.156. This helmet did not meet the minimum visibility and color requirements specified in the National Fire Protection Association (NFPA) 1971 Standard on Protective Ensembles for Structural Fire Fighting and Proximity Fire Fighting (2013 Edition).

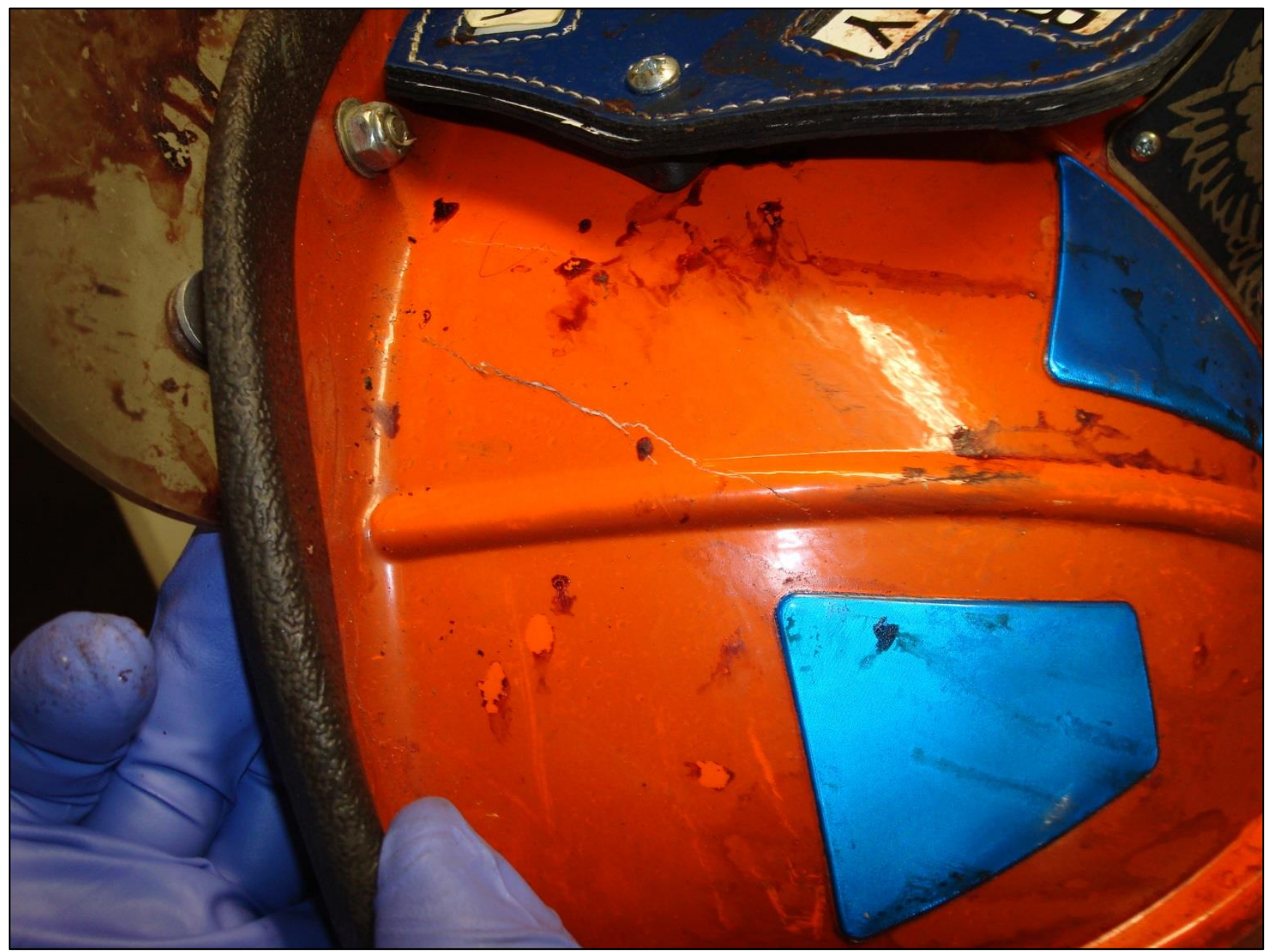

Photo 6. Close up view of the shift safety officer's helmet. Note the crack in the helmet's outer shell near the center of the photo. Also note the blue tetrahedrons on the helmet and the blue shield. (Photo NIOSH)

Based on the inspection, the protective helmet performed as intended for the event and it is not believed to have contributed to the fatality of this incident. 


\section{Shift Safety Officer Falls through Hole in Floor into Basement of Vacant Row House and Dies from Smoke Inhalation - Maryland}

The complete NPPTL evaluation reports covering the radio and helmet are available upon request.

\section{Weather Conditions}

At the time of the incident, the weather was overcast with an approximate temperature of 59 degrees Fahrenheit $\left(59^{\circ} \mathrm{F}\right)$. The relative humidity was approximately $94-96$ percent with a dew point of $57^{\circ} \mathrm{F}$. Winds were calm and a light drizzle was reported at nearby locations. $\underline{3}$

After the incident, the fire department consulted with local meteorologists about the possibility of thermal inversion conditions contributing to the smoke accumulation in the basement of the Delta exposure were the shift safety officer died. In meteorology, a temperature inversion occurs when warm air at high altitude traps colder air near the ground surface. Under normal conditions, the atmospheric temperature decreases with altitude. This allows dust, smoke and other pollutants to rise and be dispersed. In urban areas, a temperature inversion can trap smoke and other pollutants near the surface, producing smog. $\stackrel{4}{ }$ A temperature inversion likely occurred at the time of this incident. However, the weather conditions on the night of the incident are not believed to have contributed to the smoke accumulation within the basement of the vacant row house where the shift safety officer was found.

\section{Investigation}

On November 12, 2014, a 62-year-old male career lieutenant, serving as the shift safety officer (SO2), died after falling through a hole in the floor of a vacant row house. The shift safety officer fell into the basement, suffered face and head injuries, and died from smoke inhalation.

At approximately 0019 hours, the city's Fire Communication Bureau (FCB) began receiving telephone calls reporting smoke in a structure. The caller was not sure where the smoke was coming from. At 0019:32 hours, a box alarm was sounded. Following standard fire department procedures, the closest five engine companies and two truck companies along with two battalion chiefs and a medic unit were dispatched. Engine 31 (E31), Engine 6 (E6), Engine 13 (E13), Engine 33 (E33), Engine 23 (E23), Truck 5 (T5), Truck 1 (T1), Battalion Chief 2 (BC 2), Battalion Chief 6 (BC 6) and Medic 16 (M16) were dispatched. While enroute, the third-due engine company, E13, was designated as the rapid intervention team (RIT) per standard procedures. E13 acknowledged the assignment to be RIT. Companies began to arrive on scene at 0023 hours. The first due engine company, E31, dropped 3inch supply line at a hydrant and then proceeded to the front of the structure (side Alpha), approximately one and a half blocks to the east. The second due engine, E6, connected to the hydrant and pumped to E31 establishing a continuous water supply. Truck 5 staged in the street behind E31 and raised their aerial ladder to the roof of the three-story structure. Engine 13 arrived on scene and all four crew members reported to the front of the structure for RIT assignment. Battalion Chief 2 arrived on scene at 0024 hours and assumed Incident Command. Battalion Chief 2 reported a three-story brick structure with smoke showing on side Alpha. Engine 33, and Truck 1 were deployed to side Charlie. Engine 23 covered a hydrant to provide a continuous water supply to Engine 33.

The fire structure shared common brick and mortar walls with an occupied row house on side Bravo and a vacant row house on side Delta. The T5 crew used hand tools to force open the front door of the 


\section{Shift Safety Officer Falls through Hole in Floor into Basement of Vacant Row House and Dies from Smoke Inhalation - Maryland}

fire structure. The T5 lieutenant and fire fighter entered the structure and began to search for the location of the fire. As the E31crew was advancing a five-section (250 feet) 13/4 inch preconnected handline through the front door, the T5 lieutenant radioed that he had found fire on the second floor. The E31 crew advanced their handline up the front stairway located on side Bravo. As they were advancing to the second floor, a section of the handline burst so the E31 crew had to pull a second 13/4 inch preconnected handline off E31 and advance it up the front stairway. At approximately 0027 hours, Battalion Chief 6 (BC6) arrived on scene, radioed to FCB that he would be "Safety" and checked in with the Incident Commander. Per department procedures, the second due battalion chief assumes the duties of the Incident Safety Officer (ISO) until relieved by the shift safety officer. Battalion Chief 6 walked around the block to side Charlie.

At approximately 0028 hours, BC2 (the Incident Commander) radioed FCB and upgraded the incident to a working fire. Per standard procedures, one additional engine company, Engine 8 (E8), one additional truck company, Truck 16 (T16), the shift safety officer (SO2), the shift commander, and the AIRFLEX unit, a vehicle that carries additional air cylinders, portable lighting, and other equipment were dispatched. Battalion Chief 5 (BC5) was working as the acting shift commander at the time of the fire.

The T1 crew forced entry at the rear of the fire structure and the E33 advanced a 13/4 inch preconnected hand line through the rear door. The E33 crew observed fire in the rear stairwell extending up to the second floor. They used their handline to knock down the fire. Hose streams were operated at approximately 150 gallons per minute at 100 psi.

At approximately, 0032 hours, the IC radioed for the working fire units (E8 and T16) to stage west of the structure. At 0033 hours, BC6 radioed that just light smoke was showing on side Charlie. At 0034 hours, the IC radioed that the bulk of the fire was knocked down with moderate smoke conditions on all sides.

At approximately 0042 hours, the shift safety officer (SO2) arrived on-scene and reported to the IC. The IC radioed that the shift safety officer was taking over as "Safety" and BC 6 would be "Charlie Division." The shift safety officer then began a 360 degree walk-around of the incident scene. He walked around the block from side Alpha to side Bravo and down the alley to side Charlie. The shift safety officer talked to BC6 about the conditions at the rear of the structure and BC6 transferred the safety officer responsibilities to the shift safety officer.

At 0046 hours, the IC declared the fire under control and began to release crews. The crews dispatched for the working fire (E8 and T16) had remained in staging and were released without having been deployed. The acting shift supervisor (Car 5) returned to service at 0047 hours. The IC ordered the side Delta exposure to be opened up and checked for fire extension. Truck 5 forced open the front door and two fire fighters from Truck 1 began to force open the rear (side Charlie) of the side Delta exposure building. As the T1 fire fighters were working to force open the rear door and window, the shift safety officer directed them to stop. Reportedly, the shift safety officer stated they were in an unsafe condition and that crews were working inside the structure. The shift safety officer did not state 


\section{Shift Safety Officer Falls through Hole in Floor into Basement of Vacant Row House and Dies from Smoke Inhalation - Maryland}

what the unsafe condition was. During interviews, the T1 fire fighters stated that they thought it was because glass was falling down from the second story windows where the T5 and T1 crews were knocking out the side Charlie windows of the side Delta exposure building for ventilation.

When T5 forced open the front door of the side Delta exposure, heavy smoke pushed out. The IC directed the RIT crew (E13) to take a handline into the side Delta exposure in case fire had extended into the structure. The E13 crew advanced the hose line into the Delta exposure and up the steps to the second floor. They did not find any fire in the Delta exposure. Note: The E13 crew had an experienced fire fighter serving as the acting lieutenant. The T5 and T1 crews were already inside working on ventilation.

After returning from the second floor, the E13 crew walked to the rear of the first floor. They observed that all the floor boards and the floor joists had been removed at the rear of the first floor from the basement steps to the back wall, leaving a large hole in the floor (see Diagram 1). The E13 crew walked back outside to the front (side Alpha) but did not report the missing floor boards to the IC or the shift safety officer.

An electric smoke ejector (exhaust ventilation fan) was placed in the front doorway of the fire structure to clear the structure of smoke. An electric positive pressure ventilation (PPV) fan was also placed in the front doorway of the side Delta exposure by an unknown fire fighter. A T5 fire fighter observed that the PPV fan was improperly positioned so he moved the fan back to the sidewalk in front of the doorway and turned it so that it was blowing toward the front door of the Delta exposure building. The T5 fire fighter checked to make sure that there was positive pressure at the doorway by feeling for air movement from the fan.

T1 never reported to the IC that due to the shift safety officer stopping their efforts to open the rear door and window, they were not able to complete their assignment to ventilate the rear of the delta exposure.

The shift safety officer returned to side Alpha and was observed talking face-to-face with the IC. At approximately 0056 hours, the shift safety officer radioed the E13 crew for a report on the conditions on the second floor of the Delta exposure building. A E13 crew member radioed command that there was no fire, just some trapped smoke and they were working to open up the structure. The E13 crew reported that when they returned outside, they saw the shift safety officer (SO2) at side Alpha.

Photographs taken at approximately 0104 hours showed the shift safety officer in the street at Side Alpha near the incident commander (see Photo 5). 


\section{Shift Safety Officer Falls through Hole in Floor into Basement of Vacant} Row House and Dies from Smoke Inhalation - Maryland

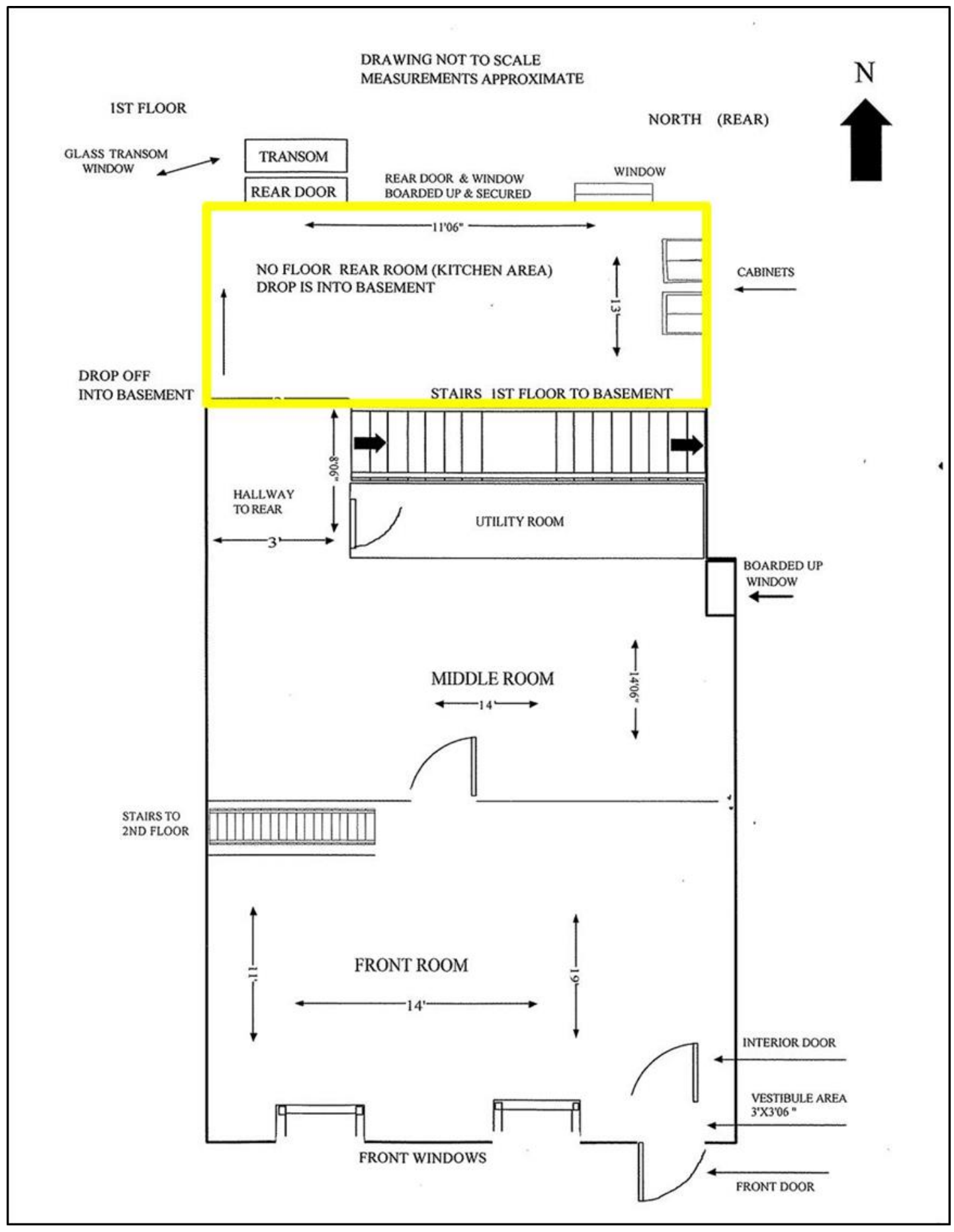

Diagram 1. First floor layout of the Delta exposure where the shift safety officer was found. The highlighted area at the rear of the first floor is the area where all flooring and joists had been removed.

(Adapted from drawing provided by Fire Department) 


\section{Shift Safety Officer Falls through Hole in Floor into Basement of Vacant Row House and Dies from Smoke Inhalation - Maryland}

One of the T5 fire fighters reported moving the PPV fan in the doorway of the Delta exposure so that the shift safety officer (SO2) could enter the Delta exposure. The shift safety officer entered the structure alone. There were no confirmed sightings or contact with the shift safety officer after this time. The safety officer's vehicle carried gas detection equipment that was not utilized at this incident.

The IC began releasing crews to return to service. BC6 returned to service at approximately 0116 hours. At approximately 0152 hours, the IC radioed dispatch that he was transferring command to Truck 5. The IC (BC2) departed the scene at approximately 0154 hours. The remaining crews worked to secure the fire structure and the Delta exposure by boarding up doors and windows. All remaining fire department staff, excluding the shift safety officer, departed the scene by 0223, which was confirmed by radio transmissions.

At approximately 0334 hours, the Fire Communication Bureau placed the shift safety officer in service without verification of his location.

At approximately 0643 hours, the city communication center received a 911 phone call from a male caller who asked to be connected to the Fire Communication Bureau. The caller reported that a fire department vehicle was parked on the wrong side of the street and in the middle of the street. He reported that he had been at the location approximately 20 minutes and nobody was around. He described the vehicle markings and the vehicle license plate number. He also identified the vehicle location by the block number and street intersection. The call ended at approximately 0646 hours. No case number was entered into the computer-aided dispatch (CAD) system.

At approximately 0647 hours, the city call taker called FCB and reported what the caller had said. The fire department dispatcher asked for the vehicle's color, license plate number and other identifying markings along with the vehicle's location. After this call ended, the fire department dispatcher discussed the call with another fire department dispatcher. The discussion ended at approximately 0653 hours and the fire dispatchers returned to their duties.

At approximately 0700 hours, the fire dispatcher who received the call realized he hadn't reported the call to his supervisor. He briefly discussed the call with the shift lieutenant but they were interrupted by calls to the FCB dispatch center and never finished the conversation.

At approximately 0708 hours the same caller called dispatch again and asked if the fire department had a vehicle at the location. The shift lieutenant took the call. The caller reported that he hadn't seen anyone around the vehicle and the back window was slightly open and he was concerned that someone might try to steal equipment from the fire department vehicle. After more discussion, the shift lieutenant attempted to contact the fire department apparatus coordinator and at 0711 the apparatus coordinator called back to fire dispatch. The fire dispatch shift lieutenant and the apparatus coordinator discussed the information provided by the caller but the vehicle was not immediately identified by the apparatus coordinator. 


\section{Shift Safety Officer Falls through Hole in Floor into Basement of Vacant Row House and Dies from Smoke Inhalation - Maryland}

At approximately 0732 hours, the caller called fire dispatch again to ask about the vehicle. The shift lieutenant took the call and asked the caller for the vehicle's license plate number. The caller provided the license plate number again. The shift lieutenant called the apparatus coordinator and gave him the license plate number. At approximately 0736 hours, the apparatus coordinator identified the vehicle as being assigned to the shift safety officer (SO2). The shift lieutenant immediately radioed over fire bands A1 and A2 for the shift safety officer 2. This was broadcast a number of times with no response. The shift lieutenant also checked the daily staff roster to identify the shift safety officer. Note: the shift safety officer normally works a 24 hour shift from 0700 to 0700 hours. A new shift safety officer (on $C$ shift) came on duty and noticed that the safety vehicle SO2 was not in quarters. He assumed the missing shift safety officer (the lieutenant working B-shift) was out on a call.

At 0743 hours, the on-duty shift safety officer (C shift) called fire dispatch and asked where SO2 was located. The call taker told the on-duty shift safety officer to hold because the shift lieutenant was working on locating the vehicle. The shift lieutenant answered the phone and spoke directly to the onduty C-shift safety officer. She asked him if he was where the vehicle was located. He stated that he was still in quarters waiting for the missing shift safety officer (the victim working B-shift) to return with the vehicle. The shift lieutenant told the on-duty shift safety officer that dispatch had received a number of phone calls reporting that the safety officer's vehicle SO2 was parked on the wrong side of the street blocking traffic and the windows were partially open, with no fire service personnel around the vehicle. Note: The shift safety officer coming on duty had previously called the missing shift safety officer's cell phone in an attempt to determine his location.

At approximately 0745 hours, the fire dispatch shift lieutenant called the fire operations shift commander and reported that there was a problem with the safety officer's vehicle being parked on the wrong side of the street blocking traffic and the missing shift safety officer could not be located. After some discussion with dispatch and the on-duty shift safety officer, at approximately 0748 hours, the shift commander directed Engine 6 to be placed out of service so that the E6 crew could go to the location and investigate.

At approximately 0824 hours the E6 crew located the missing shift safety officer in the basement of the Delta exposure. He was in a sitting position near the Side Bravo wall slumped over on his right side against a pile of debris (see Diagram 2). Emergency medical services personnel were dispatched to the scene and the shift safety officer was pronounced dead at the scene at approximately 0852 hours. 


\section{Shift Safety Officer Falls through Hole in Floor into Basement of Vacant} Row House and Dies from Smoke Inhalation - Maryland

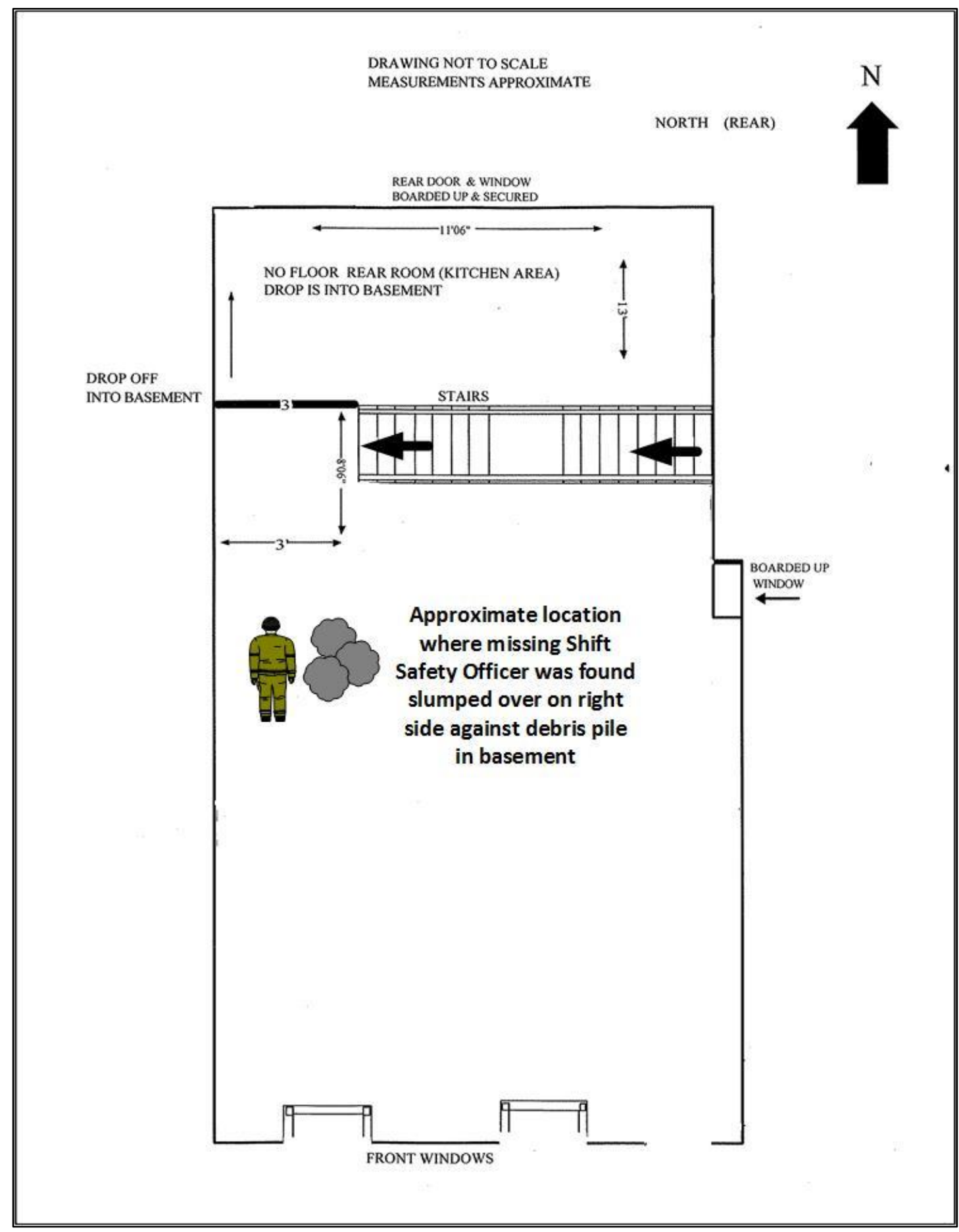

Diagram 2. Basement floor layout showing the location where the shift safety officer was found in the basement of the Delta exposure.

(Adapted from drawing provided by Fire Department) 


\section{Shift Safety Officer Falls through Hole in Floor into Basement of Vacant Row House and Dies from Smoke Inhalation - Maryland}

\section{Contributing Factors}

Occupational injuries and fatalities are often the result of one or more contributing factors or key events in a larger sequence of events that ultimately result in the injury or fatality. NIOSH investigators identified the following items as key contributing factors in this incident that ultimately led to the fatalities:

- Floor system at rear of the Delta exposure completely removed prior to incident

- Hole in floor (fireground hazard) not reported to the incident commander

- Smoke accumulation in the unventilated basement of the Delta exposure

- Ventilation in the Delta exposure was not completed

- Shift safety officer entered the Delta exposure alone

- Fireground accountability was ineffective

- Crew integrity was not maintained and single unit resources functioned alone

- Fire Communication Bureau placed shift safety officer in service without verbal confirmation of his location.

\section{Cause of Death}

The medical examiner's report listed the victim's cause of death as smoke inhalation. The manner of death was an accident. The autopsy identified a blood carbon monoxide level of 73.5 percent. Noted injuries included a broken nose and lacerations and abrasions on the forehead and nose. There was no evidence of internal head trauma.

\section{Evaluating the Effects of Ventilation}

At the request of NIOSH and the fire department, the National Institute of Standards and Technology (NIST) Fire Research Division was invited to examine and evaluate several air movement / ventilation scenarios involving the two vacant row houses involved in this incident. The vacant row houses included the fire structure and the adjoining Delta exposure structure where the shift safety officer was ultimately found. Since the cause of death was determined to be smoke inhalation and the fatality occurred in the Delta exposure building which had no fire involvement, this evaluation was conducted to determine what effect the use of the ventilation fans on the night of the fire could have contributed to the accumulation of smoke and fire gases within the basement of the Delta exposure building.

Gases flow from one space to another as a result of pressure differences, i.e. move from a space of higher pressure to a space at a lower pressure. If there is no pressure difference between one space and another, then the gases will not flow between the spaces.

Several different scenarios were examined by NIST to see if a flow path could be created through the Delta exposure building in such a way that would hold smoke in the basement of the row house or evacuate smoke out of the basement of the row house. This evaluation was conducted by NIST on December 11, 2014. Representatives of the fire department, Maryland Department of Labor, Licensing and Regulation, NIOSH and NIST were present during the evaluation. 


\section{Shift Safety Officer Falls through Hole in Floor into Basement of Vacant Row House and Dies from Smoke Inhalation - Maryland}

\section{Introduction}

When a fire occurs in a room, the combustion products (fire gases/smoke) from the fire are hotter and less dense than the surrounding air. As the fire gases get hotter they continue to expand and flow away from the fire. Once the heated fire gases have filled the upper portion of a room (hot gas layer), the gas pressure in the hot gas layer increases. This increased pressure allows the fire gases to push through openings in the room into adjacent spaces with a lower pressure.

After a fire, when the fire gases have cooled to ambient conditions, rooms in a structure may be filled with visible "cold" smoke. Because the gases have cooled and equalized with the surroundings, there is no difference in pressure to move the cold smoke out of the space. Many times fire departments will use a fan to increase the pressure of the smoke filled room and push the smoke to a lower pressure outside of the room. For this to work, a flow path must be created with the fan pressurizing the inlet to the smoke filled room to force the flow through another opening which serves as the lower pressure exhaust vent. This is the principle behind the use of positive pressure ventilation (PPV) fans.

\section{Instrumentation and Flow Path Evaluation}

Differential pressure transducers were located at various positions in the basement and on the first floor of the Delta exposure building where the victim was found. The purpose of the testing was to determine if pressure differences could be generated between the first floor and the basement in such a way that air from the basement would be exhausted. The same fans used during the night of the fire were used during the evaluation process.

An electric smoke ejector fan was located in the front doorway of the fire building and an electric PPV style fan was set up blowing at the front doorway of the Delta exposure building (see Photo 7).

\section{Findings}

In most scenarios evaluated, no pressure differences were generated with either the smoke ejector in the doorway of the fire building and/or the PPV fan blowing at the doorway of the Delta exposure building. The reason for this is that there was no flow path from either the basement or the first floor to a lower pressure vent. Given that there was a large section of the floor assembly missing from the rear of the 1st floor, the basement and the first floor effectively behave as one large compartment. The open volume of the basement/first floor and uncontrollable openings to the second and third floors, limited the ability of the electric PPV fan to create a high pressure in any part of the Delta exposure structure.

The only ventilation condition that enabled flow through the basement occurred when one of the basement windows at the front (Side Alpha) of the Delta exposure building was opened (see Photo 8). Since the first floor and the basement were similar but at slightly higher pressures (approximately 5 pascals (Pa) than the outside), air flowed from the basement out of the basement window opening. An anemometer positioned in the basement window opening showed an exhaust flow of 1 to $2 \mathrm{mph}$. This window was not opened on the night of the fire. 


\section{Shift Safety Officer Falls through Hole in Floor into Basement of Vacant Row House and Dies from Smoke Inhalation - Maryland}

Opening the rear door of the Delta exposure building created a flow path from the front door through the house to the rear. With a flow path open from the front to the rear of the row home, air movement was observed on the first floor by the stairway to the basement in excess of $5 \mathrm{mph}$, even without the PPV fan running, as a result of the pressure created by the wind outside. With the flow through the structure, air in the rear area of the basement would experience some amount of mixing with the air moving through the structure.

It should also be noted that both of the fans used in these tests, despite differences in design, had similar air velocities at the face of the fan. As a result the PPV fan did not have the capacity to create a pressure increase of $20 \mathrm{~Pa}$ or higher in the large, open structure. In other words, the PPV fan was too small to create effective positive pressure ventilation under these conditions.

\section{Summary}

A flow path with a higher pressure at the inlet vent and a lower pressure at the exhaust vent is required to move gases through the flow path. In cases where there was no clear flow path with a lower pressure exhaust vent, there was no air movement within the row home. Only when the rear door was opened did a functional flow path exist across the first floor. Even with the front and rear doors open, the air flow in the basement would still be largely unaffected. The potential for flow to move through the basement existed with the front door open and the basement windows open. However significantly higher pressures (e.g. larger fan) would be required to develop a condition to clear the basement with the basement windows open. Neither fan was properly sized to provide proper ventilation and did not contribute to the environment in the basement 
Shift Safety Officer Falls through Hole in Floor into Basement of Vacant Row House and Dies from Smoke Inhalation - Maryland

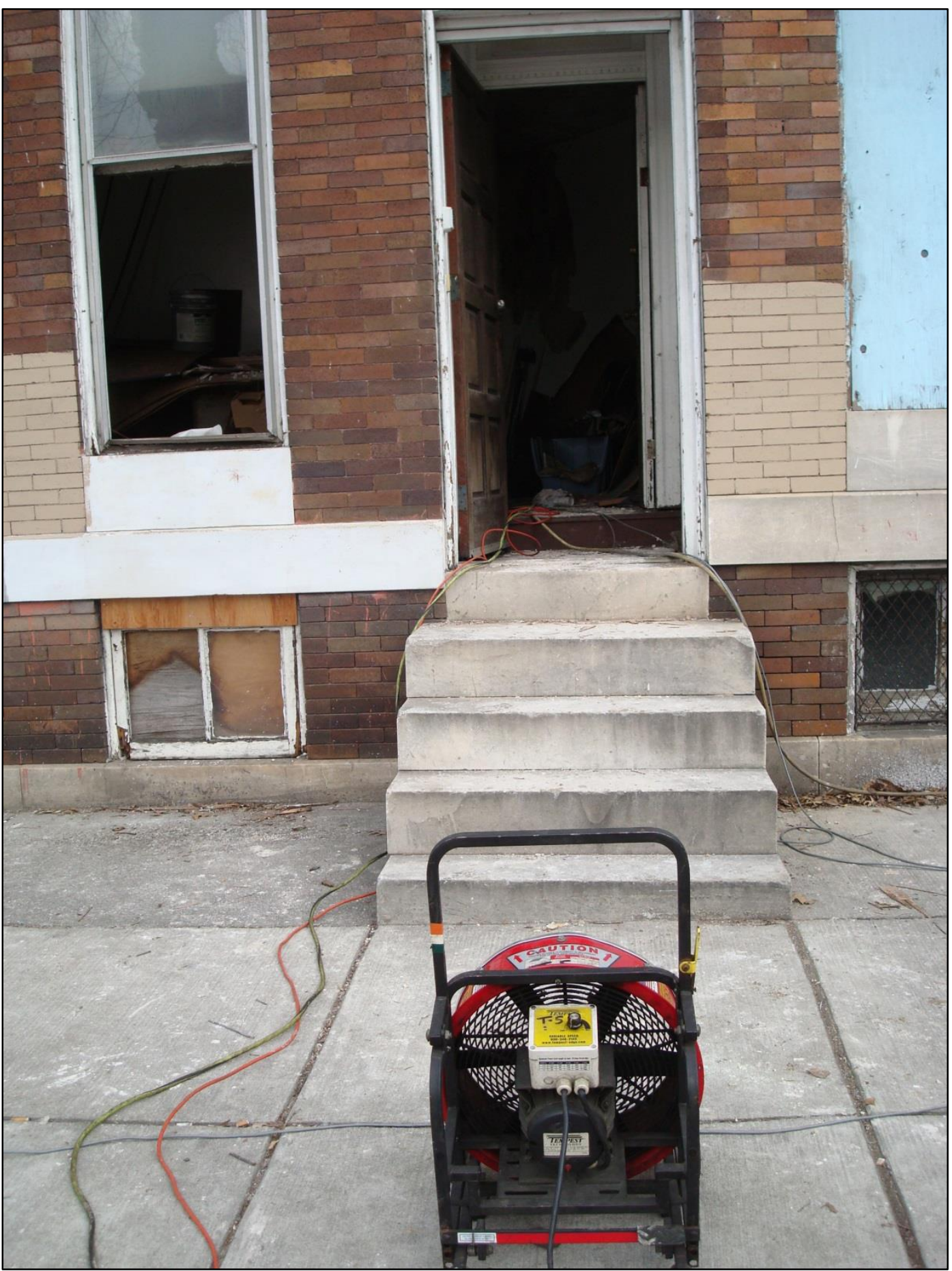

Photo 7. Ventilation fan in front of Delta exposure. Photo taken while NIST was collecting pressure and ventilation data.

(Photo NIOSH) 


\section{Shift Safety Officer Falls through Hole in Floor into Basement of Vacant Row House and Dies from Smoke Inhalation - Maryland}

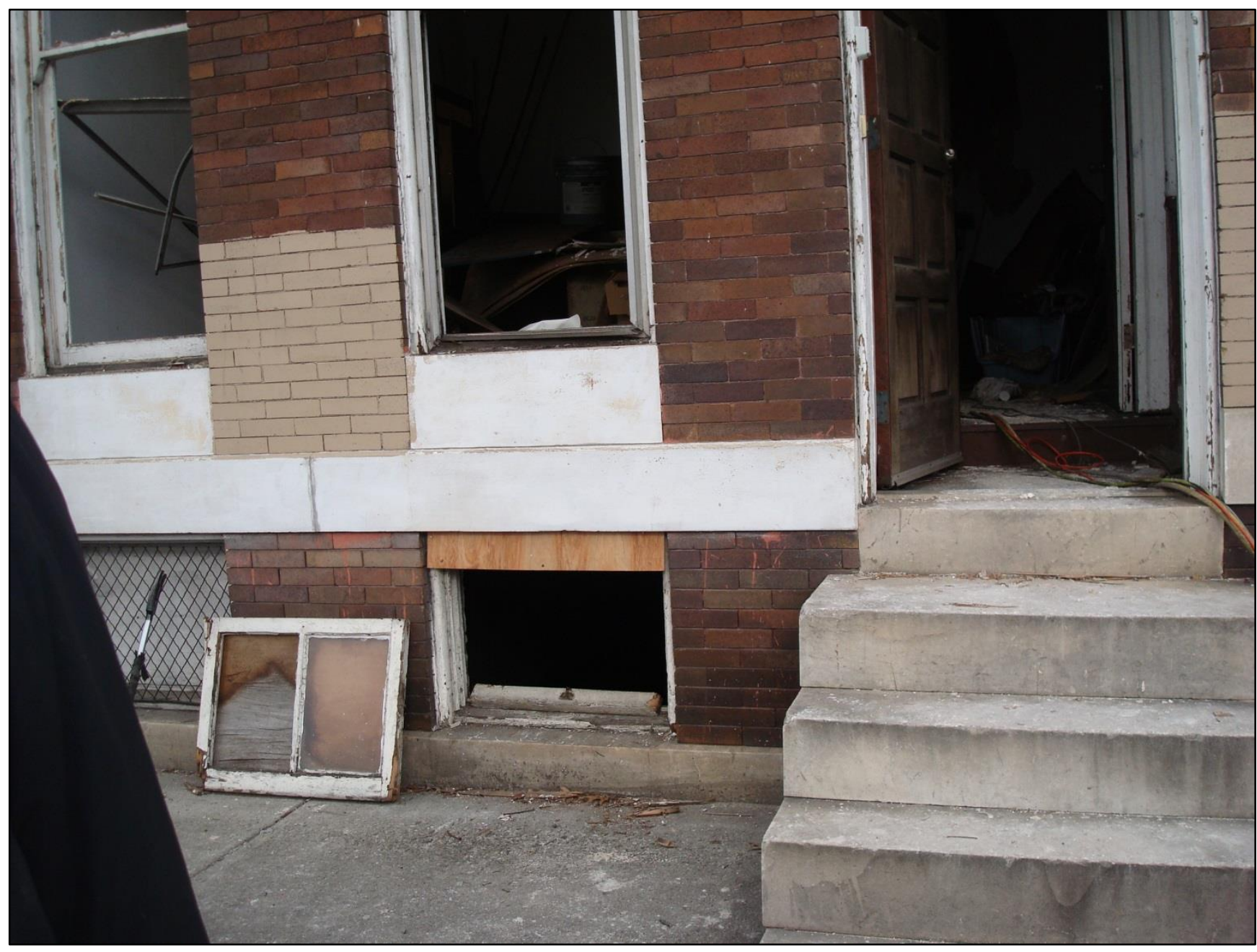

Photo 8. Photo shows basement window at Side Alpha of the Delta exposure building removed as part of the NIST data collection process. This window was not opened the night of the incident.

(Photo NIOSH)

\section{Recommendations}

Recommendation \#1: Fire departments should utilize a functional personnel accountability system, requiring a check-in and check-out procedure with the designated accountability officer or Incident Commander.

Discussion: Fire departments should review existing personnel accountability procedures to ensure that they are functional and effective. If no personnel accountability procedures exist, the fire department should develop, implement and enforce standard operating procedures that ensure a 


\section{Shift Safety Officer Falls through Hole in Floor into Basement of Vacant Row House and Dies from Smoke Inhalation - Maryland}

personnel accountability system is utilized at all emergency operations. The National Fire Protection Association (NFPA) 1561 Standard on Emergency Services Incident Management System (2008 edition), Section 4.5.1 states that the emergency services organization (ESO) shall develop and routinely use a system to maintain accountability for all resources assigned to the incident with special emphasis on the accountability of personnel. Section 4.5.3 states that the system shall include a specific means to identify and keep track of responders entering and leaving hazardous areas, especially where special protective equipment is required. Section 4.5.10 states that responders who arrive at an incident in or on marked apparatus shall be identified by a system that provides an accurate

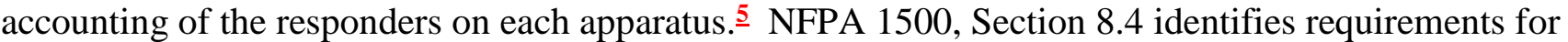
personnel accountability during emergency operations. Section 8.4.1 states that the fire department shall establish written standard operating procedures for a personnel accountability system that is in accordance with NFPA 1561, Standard on Emergency Services Incident Management System. $\underline{\mathbf{5 , 6}}$ Section 8.4.4 states that the Incident Commander shall maintain an awareness of the location and function of all companies or crews at the scene of the incident.

Personnel accountability systems can range in complexity from simple identification tags to complex electronic tracking systems. A variety of different personnel accountability systems have been used at emergency operations across the country.

The fire department involved in this incident had written standard operating procedures defining a personnel accountability system intended to meet the requirements of NFPA 1500 and NFPA 1561. The written procedures specified that the Incident Commander shall be responsible for overall personnel accountability for the incident and that the Incident Commander shall maintain an awareness of the location and function of all companies or units at the scene of the incident. The procedures also stated that the Incident Commander shall provide the use of additional accountability officers based on the size, complexity, or needs of the incident.

During this incident, the personnel accountability function remained with the IC until after the fire was placed under control and crews were placed back into service. The shift safety officer (SO2) was dispatched on the Working Fire Alarm and arrived on-scene just minutes before the fire was placed under control. SO2 reported to the Incident Commander for a briefing as per the department's procedures for the Shift Safety Officer. A photograph taken at approximately 0104 hours documented SO2 talking to the Incident Commander in the street in front of the row houses (see Photo 5). Soon after, SO2 entered the Delta exposure alone. The Incident Commander radioed dispatch that he was transferring command to Truck 5 at approximately 0152 hours. The Incident Commander left the incident scene at 0154 hours. All remaining fire department staff excluding the SO2 left the incident scene by 0223 hours. Dispatch marked the shift safety officer in station at 0334 hours without attempting to verify his location. At some point after 0104 hours, Incident Command lost accountability of SO2. Fire departments should ensure that personnel accountability procedures are functional so that accountability is maintained for all personnel dispatched to an emergency incident. 


\section{Shift Safety Officer Falls through Hole in Floor into Basement of Vacant Row House and Dies from Smoke Inhalation - Maryland}

Recommendation \#2: Fire departments should ensure that the Incident Commander accounts for all resources before dissolving command.

Discussion: As noted above, personnel accountability at an emergency response is of the utmost importance. The Incident Commander and any designated accountability officers need to be aware of the location and job assignment for all fire department personnel at the emergency incident scene at all times. Fire departments should have procedures in place to ensure that personnel accountability is maintained at all times during an emergency response. This includes from the initial dispatch until the last fire department personnel leaves the incident scene. During this incident, the personnel accountability function remained with the IC until after the fire was placed under control and crews were placed back into service. A separate accountability officer was not designated.

This fire department has written procedures detailing fireground operations and incident command functions including the transfer of command. These procedures focus on the transfer of command as an incident grows in size and complexity. These procedures provide limited guidance on fireground personnel accountability as the incident is winding down. The Shift Safety Officer was seen talking with the Incident Commander at approximately 0104 hours and entered the Delta exposure alone soon after. The Incident Commander radioed dispatch that he was transferring command to Truck 5 at approximately 0152 hours. The Incident Commander left the incident scene at 0154 hours. All remaining fire department staff excluding the shift safety officer left the incident by 0223 hours. Dispatch marked the shift safety officer in station at 0334 hours without attempting to verify his location.

\section{Recommendation \#3: Fire departments should train fire fighters on the principles of situational} awareness.

Discussion: All fire fighters operating at an incident should maintain situational awareness and conduct a continuous risk assessment throughout the incident, reporting unsafe or changing conditions to the Incident Commander. Fire fighters need to understand the importance of situational awareness and personal safety on the fire ground. Essentials of Fire Fighting and Fire Department Operations ${ }^{7}$ defines situational awareness as an awareness of the immediate surroundings. On the fire ground, every fire fighter should be trained to be constantly alert for changing and unsafe conditions. This applies not only to the conditions found within a burning structure, but to exposure buildings and the exterior fireground as well. Even though a safety officer may have been designated for an incident, all personnel are obligated to remain alert to their immediate surroundings.

The ability to maintain situational awareness is reliant on a fire fighter's training, judgment and personal condition. These factors must come together every time a fire fighter goes to an emergency incident especially those involving a low-frequency, high risk event such as structural fire-fighting, wildland fire-fighting, trench rescue, high angle rescue, or any of the wide arrays of emergencies fire fighters are called upon to mitigate. A lack of competency, or even a temporary lack of focus, can lead to a chain of events that may be catastrophic or even fatal. $\underline{8-9}$ 


\section{Shift Safety Officer Falls through Hole in Floor into Basement of Vacant Row House and Dies from Smoke Inhalation - Maryland}

To properly train personnel to maintain situational awareness on the fireground or at any emergency incident, a fire department has to develop and utilize effective scenario based training. Training fire fighters to maintain situational awareness on the fireground needs to include building construction, fire behavior, fireground tactics and strategy, ventilation, and other fireground operations. This is a continuous process that is initiated in recruit school and continues through a fire fighter's entire fire service career..

Fire fighters need to understand the importance of situational awareness, personal safety, and company/crew accountability on the fireground. The fireground dangers and hazards can and do change as an incident evolves and the event duration increases. Situational awareness is defined as recognition of the immediate surroundings. On the fireground, every fire fighter should be trained to be constantly alert for changing and unsafe conditions related to their immediate surroundings. Each and every fire fighter needs to be responsible and accountable for their own safety, as well as team members and others working in the immediate area. This applies not only to the conditions found within a burning structure, but to the exterior fireground as well. $\underline{7}$

The United States Coast Guard says that, "Situational Awareness is the ability to identify, process, and comprehend the critical elements of information about what is happening to the team with regards to the mission." In other words in order to have "situational awareness" you must constantly know what is happening around you, and where you are in relation to threats..

The need for fire fighters to maintain situational awareness is paramount. A loss of situational awareness can lead directly to disorientation. Disorientation far too often leads to a fire fighter line of duty death. In addition, a perceived lack of a threat can lead directly to complacency or an unrealistic feeling of comfort in one's environment. Situational awareness is a cognitive skill; it can be taught. In order to have situational awareness, you must be able to perceive the threat, comprehend the threat and predict what effect that threat may have on you. These elements: Perceive, Comprehend and Predict form the cornerstone of maintaining complete situational awareness. $\underline{8}$

In this incident, the shift safety officer (SO2) entered the Delta exposure building as crews were finishing up operations and preparing to leave the scene. He entered the structure alone sometime shortly after 0104 hours. He was not wearing an SCBA or a PASS device. It is likely that he was unaware of the hazard of the missing floor located at the rear of the exposure building and subsequently fell into the basement. The shift safety officer was alive after his fall and continued to breathe, eventually succumbing to smoke inhalation with an autopsy blood carbon monoxide level of $73.5 \%$

\section{Recommendation \#4: Fire departments should train and empower all fire fighters to report unsafe conditions to Incident Command.}

Discussion: The International Association of Fire Chiefs (IAFC), Safety, Health and Survival section developed the "Rules of Engagement for Structural Fire Fighting." The rules of engagement have been developed to assist both the fire fighter and the Incident Commander (as well as command team 


\section{Shift Safety Officer Falls through Hole in Floor into Basement of Vacant Row House and Dies from Smoke Inhalation - Maryland}

officers) in risk assessment and "Go or No-Go" decisions. The fire ground creates a significant risk to fire fighters and it is the responsibility of the Incident Commander and command organization officers to minimize fire fighter exposure to unsafe conditions and stop unsafe practices. $\underline{10}$

The IAFC Rules of Engagement can assist the Incident Commander, company officers, and fire fighters (who are at the highest level of risk) in assessing their situational awareness. One principle applied in the rules of engagement is that fire fighters and the company officers are the members most at risk for injury or death and will be the first to identify unsafe conditions and practices. The rules integrate the fire-fighter into the risk assessment decision making process. These members should be the ultimate decision makers as to whether it's safe to proceed with assigned objectives. Where it is not safe to proceed, the rules allow a process for that decision to be made while still maintaining command unity and discipline.

One of the IAFC Rules of Engagement for Firefighter Survival states "You Are Required to Report Unsafe Practices or Conditions That Can Harm You. Stop, Evaluate, and Decide." This Rule applies the principles of crew resource management by encouraging all firefighters to apply situational awareness and be responsible for their own safety and that of other firefighters. In a sense all firefighters become the additional eyes and ears of the incident commander and alerting him (or the immediate supervisor) to unacceptable situations. No fire attack or building is worth the life of a firefighter or a preventable (sometimes career ending) injury. The intent of this Rule is to allow any member to report a safety concern through a structured process without fear of penalty.

One of the key tenants of the National Fallen Firefighter Foundation (NFFF) is their 16 Life Safety Initiatives. The 16 Firefighter Life Safety Initiatives (FLSI) were jointly developed by representatives of the major fire service constituencies in 2004 at a Firefighter Safety Summit in Tampa, FL. At that time, the National Fallen Firefighters Foundation was tasked with promulgating the Initiatives throughout the fire service, and developing material to support their implementation. $\underline{11}$

Live Safety Initiative number 4 is "Empowerment - All firefighters must be empowered to stop unsafe practices." While this may appear to be a challenging or even controversial statement, it simply means that every organization should provide an environment that allows its members to speak up regarding personal and organizational safety; without negative consequences for doing so (within a prescribed context), and without decentralizing the authority of the formal leader. The goal is to have every member fully engaged during an emergency incident with a focus on doing the work in a proficient manner and looking out for one another to avoid injuries and potential line of duty death. $\underline{11}$

Every firefighter is responsible for their individual safety and the safety of other firefighters. Each firefighter is responsible for identifying risks and hazards and reporting them. Supervisors are responsible for accepting reports regarding safety concerns without penalizing the firefighter and properly acting on the report to ensure the safety of firefighters.

In this incident, fire fighters working inside the Delta exposure observed the missing floor at the rear of the structure but this information was never reported to Incident Command or the shift safety officer. 


\section{Shift Safety Officer Falls through Hole in Floor into Basement of Vacant Row House and Dies from Smoke Inhalation - Maryland}

This information could have allowed the IC and/or the shift safety officer to take action to prevent exposure to this hazard by establishing a hazard control zone. Late in the incident, the shift safety officer entered the structure alone. It is believed that he fell through the hole into the basement and later succumbed to smoke inhalation.

\section{Recommendation \#5: Fire departments should train all fire fighters and officers to report when tasks are completed or cannot be completed to their officer or the Incident Commander.}

Discussion: The Incident Commander depends upon two-way communication and continual feedback at emergency incidents in order to manage the incident. This aids the Incident Commander in the decision making process and is especially true at structure fires and large incidents where the IC may not have visual contact with all fire fighters and may not be able to view the entire incident scene from the command post.

This incident occurred in the middle of a series of 12 connected row houses that filled an entire city block. The Incident Commander was positioned in the street on side Alpha facing the block of row houses. In order to facilitate incident management, the second-due battalion chief was designated Charlie Division and also the incident Safety Officer per standard departmental procedures on the first alarm. He operated on the Charlie side throughout the incident. When the shift safety officer (SO2) arrived on-scene, he assumed the incident Safety Officer role. After the fire was brought under control in the fire building, the IC directed crews to open the rear of the Delta exposure to release trapped smoke and help clear the structures. Members of a truck company were working to open the rear door and window at ground level on the Delta exposure when SO2 ordered them to stop because they were in an unsafe position. The truck company members moved to complete other assignments and SO2 returned to side Alpha. The IC was not aware that the rear of the structure was not opened for ventilation. If the rear of the Delta exposure had been opened, the truck company members and also the shift safety officer may have observed the missing floor section and taken action to prevent exposure to this hazard by establishing a hazard control zone. SO2 later entered the Delta exposure alone through the front door and fell into the basement, succumbing to smoke exposure.

Additionally, NFPA 1561 Standard for an Emergency Services Incident Management System, Section 5.9.6.11 of Chapter 5 states "At an emergency incident where activities are judged by the incident safety officer as posing an imminent threat to responder safety, the incident safety officer shall have the authority to stop, alter, or suspend those activities." Section 5.9.6.11.1 states "The incident safety officer shall immediately inform the incident commander of any actions taken to correct imminent hazards at the emergency scene." $\underline{\underline{5}}$

Ventilation testing by NIST determined that the only condition where a functional flow path across the first floor of the Delta exposure occurred when both the front and rear doors were open. Even with the front and rear doors open, the NIST testing determined that the air flow in basement would still be largely unaffected. See Pages 25-28 for more information. 


\section{Shift Safety Officer Falls through Hole in Floor into Basement of Vacant Row House and Dies from Smoke Inhalation - Maryland}

Recommendation \#6: Fire departments should ensure that every fire fighter on the fire ground utilizes a Personal Alert Safety System (PASS) device including the ability to provide PASS devices for personnel operating in a potentially dangerous environment not requiring the use of selfcontained breathing apparatus.

Discussion: Every fire fighter who may be required to enter an immediately dangerous-to-life-orhealth (IDLH) environment should be equipped with a personal alert safety system (PASS) device meeting the requirements of the NFPA 1982 Standard on Personal Alert Safety Systems (2013 edition or the latest edition). $\underline{\mathbf{1 2}}$

NFPA 1500 Standard on Fire Department Occupational Safety and Health Program (2013 edition), Chapter 7.1 states the fire department shall provide each member with protective ensembles, ensemble elements, and protective equipment designed to provide protection from hazards to which the member is likely to be exposed and that is suitable for the tasks the member is expected to perform. - Chapter 7.2.1 states that members who engage in or are exposed to the hazards of structural fire fighting shall be provided with and shall use a protective ensemble that shall meet the applicable requirements of NFPA 1971 Standard on Protective Ensembles for Structural Fire Fighting and Proximity Fire Fighting. $\underline{2}$ NFPA 1500, Chapter 7.16.2 states that each member shall be provided with, use, and activate his or her PASS devices in all emergency situations that could jeopardize that person's safety due to atmospheres that could be IDLH, in incidents that could result in entrapment, in structural collapse of any type, or as directed by the incident commander or the incident safety officer. Annex A to NFPA 1500 (A7.16.2) states that the mandatory use and operation of a PASS by fire fighters involved in rescue, fire suppression, or other hazardous duty is imperative for their safety. The primary intent of this device is to serve as an audible device to warn fellow fire fighters in the event a fire fighter becomes incapacitated or needs assistance. Past fire fighter fatality investigation reports document the critical need to wear and operate PASS devices when fire fighters operate in hazardous areas. Investigation results show that fire fighters often failed to activate the PASS unit prior to entering a hazardous area. Training and operational procedures are imperative to ensure activation of the PASS whenever PASS devices are used.

In this incident the shift safety officer was dressed in turnout gear including structural fire fighting pants, coat, boots, and helmet. He was not wearing a self-contained breathing apparatus and did not have a stand-alone PASS device. The presence of an activated and properly functioning PASS device would have sounded an alarm tone after he became motionless in the basement, potentially alerting fire fighters still on the scene to his location. The shift safety officer arrived on-scene after fire suppression operations had begun and did not enter the structure until the fire had been extinguished. However, as noted in NFPA 1500, it is good practice to wear a full protective ensemble (including SCBA) whenever members are engaged in or exposed to the hazards of structural fire fighting. In cases where it is determined that an SCBA is not necessary but fire fighters could be exposed to other common fireground hazards such as collapse and entrapment, fire fighters should be provided with stand-alone PASS devices. This incident highlights why the use of PASS devices meeting the requirements of NFPA 1982 (2013 Edition, or the most current edition), by all fire service members is highly recommended. 


\section{Shift Safety Officer Falls through Hole in Floor into Basement of Vacant Row House and Dies from Smoke Inhalation - Maryland}

\section{Recommendation \#7: Fire departments should provide Battalion Chiefs and Chief Officers with a staff assistant or chief's aide to help manage information and communication.}

Discussion: A chief's aide, staff assistant, or command technician is a position designed to assist an IC with various operational duties during emergency incidents. The chief's aide can be an essential element for effective incident management. At an emergency incident, the staff assistant can assist with key functions such as: managing the tactical worksheet; maintaining personnel accountability of all members operating at the incident (resource status and deployment location); monitoring radio communications on the dispatch, command, and fireground channels; control information flow by computer, fax, or telephone; and, access reference material and pre-incident plans. The personnel accountability system is a vital component of the fire fighter safety process. The system is designed to account and track personnel as they perform their fireground tasks. In the event of an emergency or "Mayday," the personnel accountability system must be able to provide the rapid accounting of all responders at the incident. This is one of the chief's aide's essential responsibilities. Another important function is the role of a driver in addition to their role as part of the command team. Chief Officers are required to respond quickly to emergency incidents. In their response, they have to be fully aware of heavy traffic conditions, construction detours, traffic signals, and other conditions. More importantly, the chief officer must also monitor and comprehend radio traffic to assess which companies are responding, develop a strategy for the incident based upon input from first arriving officers, develop and communicate an incident action plan which defines the strategy of the incident. A chief's aide can assist the battalion chief or chief officer in processing information without distraction and complete the necessary tasks enroute to the scene. $\underline{\underline{13}}$

The fire department involved in this incident assigned aides to Chief officers at the Shift Commander rank and above who perform administrative duties, drive the chief officer's vehicle, and assist on the fire ground with communications and accountability as necessary. Battalion Chiefs are not assigned chief aides. Thus, the Battalion Chief is responsible for the operation of their vehicle during emergency responses, in addition to collecting and analyzing information about the incident for a number of sources. Departments should consider the aide to be an individual that has the experience and authority to conduct the required tasks. Other potential roles for the chief's aide include assisting with the initial size-up, completing a 360-degree size-up, coordinating progress reports from sector/division officers and many others. The aide position can be used as a training position to help facilitate officer development. There are non-emergency functions for the chief's aide that are vital to the daily operations of the department. Some jurisdictions assign a chief's aide to command officers to perform daily administration functions (such as position staffing and leave management). In this incident, the Acting Shift Commander was dispatched on the "working fire" alarm, arrived on-scene at approximately 0034 hours and went back in service at 0154 hours after the fire was placed under control. A chief's aide or staff assistant could have helped the Incident Commander with tasks such as driving to the scene, accountability, radio communications, and scene size-up. 


\section{Shift Safety Officer Falls through Hole in Floor into Basement of Vacant Row House and Dies from Smoke Inhalation - Maryland}

Recommendation \#8: Fire departments should ensure that single resource units (e.g. safety officers, fire investigators, etc.) do not function alone in IDLH environments at emergency scenes.

Discussion: From the moment a fire fighter enters the fire service, they are taught that they should never work alone. Fire fighters are trained to work in teams of two or more and functioning as a single resource is strongly discouraged. The OSHA Respiratory Protection Standard, Title 29, Code of Federal Regulations (CFR) Part 1910.134 includes language establishing procedures for interior structural firefighting. Paragraph 1910.134(g)(4)(i) requires that at least two employees enter the IDLH atmosphere and remain in visual or voice contact with one another at all times. $\underline{14}$

The publication Fire Department Incident Safety Officer by David W. Dodson serves as a guide for the incident safety officer (ISO) to help achieve the goal of preventing fire fighter injuries and deaths. This publication states that as part of this process, "Effective ISOs always try to set a good example while performing their duties. Often, it is the habits and self-discipline that an incident safety officer displays that influence others - a passive trigger to safe behavior. To illustrate, ISOs should always, without fail, participate in the crew accountability system. Likewise, they should use appropriate PPE, follow department policies, and obey zone markers. Because ISOs often work alone - contrary to most fire service tenets - they are usually outside the hazard area and looking in, and this practice is acceptable.

However, to set a good example, ISOs working alone should follow basic guidelines:

- Always be in sight of another responder.

- Always be within shouting distance of another responder.

- Let somebody know where you are going if you are taking a tour of the incident scene.

- Don't walk into, or breathe, smoke.

It is counterproductive for the ISO to be viewed as working unsafely. ISOs should evaluate their own environment and exposure, making the adjustments necessary to act safely. Here are some examples: - In the unusual case where ISO need to go into an IDLH environment or into a hot zone, they should request a partner, use appropriate PPE and SCBA, and be tracked just like any other assigned crew.

- When performing reconnaissance around a building, ISOs are likely to walk into an area where no responder is visible (if you cannot see anyone, then nobody can see you). In these cases, ask for a partner to go with you. If no one is available, walk to the Bravo-Charlie corner, then walk back around the A-side to see the Charlie-Delta side - and have someone on the Aside keep you in their vision.

- ISOs need to self-monitor their rehab needs: Stay hydrated and eat something if you have been on-scene longer than two hours. Take steps to minimize the effects of thermal stress on your thinking ability." $\underline{15}$

These recommendations apply to all single resource units including safety officers, fire investigators, division / group supervisors and anyone working on the fireground or at an emergency incident. Although fire fighters may be permitted to operate independently and in many cases alone, every 


\section{Shift Safety Officer Falls through Hole in Floor into Basement of Vacant Row House and Dies from Smoke Inhalation - Maryland}

repetition of the act of working alone reinforces the false belief that it is safe to do so, or that the inherent level of risk is low and therefore acceptable. Incident commanders should require that single resource units to be partnered with another similar single resource and/or be supported by a crew of other responders whose primary role is to ensure the safety of such resources. The responsibility of the IC to ensure the safety of all personnel is paramount. They must ensure that sufficient resources are summoned to ensure that all functions can be safety completed.

\section{Recommendation \#9: Fire departments should ensure that Mayday training program(s) are developed and implemented so that they adequately prepare fire fighters to call a Mayday.}

Discussion: The first and foremost priority for fire fighter safety is not getting oneself into a situation that could potentially cause injury or death. The fire fighter must maintain situational awareness at all times while operating on the fireground. Fire fighters must understand that when they are faced with a life-threatening emergency, there is a very narrow window of survivability, and any delay in egress and/or to transmission of a Mayday message reduces the chance for a successful rescue. Knowledge and skill training on how to prevent a mayday situation and how to call a mayday should begin and be mastered before a fire fighter engages in fireground activities or other immediately dangerous to life and health environments. Beginner fire fighter training programs should include training on such topics as air management; familiarity with an SCBA, a radio, or PPE; crew integrity; reading smoke, fire dynamics, and fire behavior; entanglement hazards; building construction; and signs of pending structural collapse. Fire fighters must be able to recognize when they find themselves in a questionable position (dangerous or not) and be trained on procedures for when and how a mayday should be called. A fire fighter's knowledge, skill, and ability to declare a mayday must be at the mastery level of performance. This performance level should be maintained throughout their career through training offered more frequently than annually. $\underline{\underline{16}}$

Fire departments must understand that each fire fighter may have a different interpretation of what is life-threatening. The ability of a fire fighter to call a Mayday is a complicated behavior that includes the affective, cognitive, and psychomotor domains of learning and performance. $\underline{17,18}$ Any delay in calling a Mayday reduces the chance of survival and increases the risk to other fire fighters trying to rescue the downed fire fighter. This incident illustrates the need for fire fighters to be given specific training on mayday procedures for determining when a Mayday must be called.

No rules are established for determining when a mayday must be called, and mayday training is not included in the job performance requirements in NFPA Fire Fighter 1 or 2 standards. It is up to the authority having jurisdiction to train members for emergency operations $\frac{6,19}{}$ and to develop rules and performance standards for a fire fighter to call a mayday. The National Fire Academy (NFA) has two courses addressing the fire fighter mayday doctrine: Q133 Firefighter Safety, Calling the Mayday, a 2hour program covering the cognitive and affective learning domain of the fire fighter Mayday doctrine; and H134 Calling the Mayday: Hands-on Training, an 8-hour course covering the psychomotor learning domain of the fire fighter Mayday doctrine. These courses are based on the military methodology used to develop and teach ejection doctrine to fighter pilots. A training CD is available to fire departments free of charge from the U.S. Fire Administration Publications Office $\frac{17,20}{2}$ The NFA 


\section{Shift Safety Officer Falls through Hole in Floor into Basement of Vacant Row House and Dies from Smoke Inhalation - Maryland}

Mayday courses present specific mayday parameters or rules for determining when a fire fighter must call a mayday. The courses may help fire departments in developing and teaching mayday procedures for fire fighters. Also, NFPA 1001 Standard for Fire Fighter Professional Qualifications, includes job performance requirements related to the fire fighter calling for assistance (such as a mayday situation). $\underline{18}$

The IAFF Fire Ground Survival program is another resource fire departments can use and was developed to ensure that training for mayday prevention and mayday operations are consistent between all fire fighters, company officers, and chief officers. $\underline{\mathbf{1 6}}$ No Mayday was called during this incident, even though the shift safety officer had a functional radio.

Any Mayday communication must contain the location of the firefighter in as much detail as possible and, at a minimum, should include the division (floor) and quadrant. It is imperative that firefighters know their location when in IDLH environments at all times to effectively be able to give their location in the event of a Mayday. Once in distress, firefighters must immediately declare a Mayday. The following example uses LUNAR (Location, Unit, Name, Assignment/Air, Resources needed) as a prompt: "Mayday, Mayday, Mayday, Division 1 Quadrant C, Engine 71, Smith, search/out of air/vomited, can't find exit." When in trouble, a firefighter's first action must be to declare the Mayday as accurately as possible. Once the IC and RIT know the fire fighter's location, the firefighter can then try to fix the problem, such as clearing the nose cup, while the RIT is enroute for rescue. $\underline{\underline{21}}$

A fire fighter who is breathing carbon monoxide (CO) quickly loses cognitive ability to communicate correctly and can unknowingly move away from an exit, other fire fighters, or safety before becoming unconscious. Without the accurate location of a downed fire fighter, the speed at which the RIT can find them is diminished, and the window of survivability closes quickly because of lack of oxygen and high CO concentrations in an IDLH environment. $\underline{17,20-21}$

\section{Recommendation \#10: Fire departments should ensure that dispatch centers positively confirm the status of all resources before clearing an event.}

Discussion: The dispatch center is an important part of any emergency operation and provides valuable assistance and support to the incident commander. The dispatch center can provide assistance to the incident commander to help with accountability and resource tracking. The dispatch center can remind the incident commander at regular intervals how much time has transpired since crews first arrived on scene and can also prompt the IC to conduct personnel accountability rollcalls at predetermined regular intervals such as every 10 or 20 minutes. The dispatch center should mark the time that units go enroute, arrive on scene and the time that units are placed back into service.

In this incident, the incident commander IC began releasing crews to return to service shortly after the fire was brought under control at approximately 0046 hours. BC6 returned to service at approximately 0116 hours. At approximately 0152 hours, the IC radioed dispatch that he was transferring command to Truck 5. The IC (BC2) departed the scene at approximately 0154 hours. All remaining fire 


\section{Shift Safety Officer Falls through Hole in Floor into Basement of Vacant Row House and Dies from Smoke Inhalation - Maryland}

department staff excluding the shift safety officer departed the scene by 0223, which was confirmed through radio transmissions.

At approximately 0334 hours, the Fire Communication Bureau placed the shift safety officer in service without verification of his location. A process requiring positive verbal confirmation that a unit has cleared an event could have identified that the shift safety officer was missing much sooner.

\section{Recommendation \#11: Fire departments should ensure that dispatch centers forward all reports of suspicious or unusual events to the appropriate authorities in a timely manner.}

Discussion: During this incident, the dispatch center began receiving phone calls around 0647 hours reporting a fire department vehicle was parked in a travel lane of a busy street facing the wrong direction and the vehicle appeared to be unattended. At least one caller provided dispatch with the vehicle's license plate number and other identifying information. The fire department's shift supervisor was notified at approximately 0715 hours and following a series inquiries, an engine company was dispatched to investigate at approximately 0748 hours. The shift safety officer (SO2) was already deceased when he was located at approximately 0824 hours in the basement of the Delta exposure structure.

All units that responded to the row house fire communicated with dispatch when they left the scene by 0223 hours except for SO2. At some point, dispatch realized that SO2 hadn't cleared the scene. Dispatch marked the shift safety officer in station at 0334 hours without attempting to verify his location. The shift safety officer entered the structure alone at some time after 0104 hours and succumbed to smoke exposure in the basement sometime before being located at 0824 hours.

Recommendation \#12: Fire departments should consider conducting evaluations of their emergency incident activities to determine the role complacency contributes to unsafe actions and develop strategies to combat such complacency.

Discussion: Fire departments need to consider the conduct regular evaluations of their emergency incident activities to identify areas in which the department may be vulnerable to the risk of fire fighter injury and death. This process should include determining the role that complacency contributes to unsafe actions. The National Fallen Firefighters Foundation (NFFF), in coordination with the U.S. Fire Administration (USFA), has developed an online Vulnerability Assessment Tool that will provide fire departments with a systematic process to evaluate risk and ultimately reduce the threat of firefighter injuries and deaths. $\underline{22}$

Vulnerability is a term used in the insurance and technology industries, and refers to an aspect of an organization's culture or operations that is likely to result in a negative outcome. In fire service operations, that negative outcome can include a firefighter injury or fatality. A vulnerability assessment is the process of identifying, quantifying and prioritizing the vulnerabilities within an organizational system, such as a fire department. For instance, your firefighters may be at risk because 


\section{Shift Safety Officer Falls through Hole in Floor into Basement of Vacant Row House and Dies from Smoke Inhalation - Maryland}

you do not have or do not enforce a mandatory seat-belt policy. Resources will help you develop and support enforcement of such a policy. $\underline{22}$

At the end of the process, users have a customized report identifying areas of vulnerability linked to firefighter injuries and deaths. Each report contains suggestions for "risk reduction alternatives" specific to identified vulnerabilities and provides pertinent industry standards and guidelines to address the identified concerns. Fire departments can then use this analysis to develop operational and strategic plans to implement the risk reduction recommendations necessary to minimize or eliminate predictable causes of line-of-duty injuries and deaths. $\underline{\underline{22}}$

In this incident, the shift safety officer's vehicle carried gas detection equipment that could have been used to sample for the presence of carbon monoxide in the fire building and the Delta exposure, but was not used during the incident. The use of a gas detector could have warned the shift safety officer of the dangerous accumulation of carbon monoxide in the building.

Recommendation \#13: Fire departments should ensure that when Rapid Intervention Teams (RIT) are moved into operational roles, they are replaced with another functional Rapid Intervention Team.

Discussion: Although there is no evidence that this recommendation would have prevented this fatality, it is being provided as a reminder of a good safety practice. During this incident, the fire department followed established procedures in dispatching a third engine company to serve as the Rapid Intervention Team. While enroute, the Fire Communication Bureau radioed Engine 13 to advise them of their assignment and Engine 13 acknowledged that they were the RIT. Upon arrival, Engine 13 assumed the RIT function. These actions are necessary to ensure that a team of fire fighters is on location to support incident operations as required by the OSHA 2-in 2-out rule in the Respiratory Protection Standard $\underline{14}$ and in NFPA 1500 Fire Department Occupational Safety and Health Program, Chapter 8.8 Rapid Intervention for Rescue of Members. $\underline{6}$ The timely dispatch of sufficient resources to provide for a dedicated RIT as part of the first alarm assignment is critical given that empirical evidence suggests that a significant percentage of fireground-related emergencies occur within the first 20-minutes after fire fighters arrive at a working fire.

After the fire was placed under control and standby resources were released to go back into service, the RIT was given an operational assignment to deploy an attack hose line into the Delta exposure building and search for possible fire extension. At this point, there was no longer a functional RIT in place. It is equally important for the incident commander to replace a RIT team that has been deployed to another function. 


\section{Shift Safety Officer Falls through Hole in Floor into Basement of Vacant Row House and Dies from Smoke Inhalation - Maryland}

Recommendation \#14: Fire departments should ensure that the proper personal protective equipment meeting the applicable requirements of the National Fire Protection Association (NFPA) is used at all times.

Discussion: Although there is no evidence that this recommendation would have prevented this fatality, it is being provided as a reminder of a good safety practice. NFPA 1561, Standard on Emergency Services Incident Management System, Chapter 5.9.6 defines the role and responsibility of the Safety Officer within the structure of command. Chapter 5.9.6.5 states the safety officer and assistant safety officer(s) shall be specifically identifiable on the incident scene. Annex A, section A.5.9.6.5 states that this can be accomplished by wearing a highly visible vest, helmet, or other indicator. A specific color or design is not identified. $\underline{5}$

The publication Fire Department Incident Safety Officer by David W. Dodson notes that while no standard exists for the safety officer's visibility requirements, most people associate the color green with safety. The National Safety Council uses a green cross as their symbol and the Fire Department Safety Officer's Association uses a green Maltese cross as its symbol. This publication states that the incident safety officer should wear a high-visibility vest that clearly states "SAFETY". Upon seeing the safety vest, fire-fighting crews often stop an unsafe action or withdraw from an unsafe position. This self-correction is desirable on-scene; the ISO can then concentrate on other items of concern. To maximize this trigger, the SAFETY vest should be instantly recognizable from a distance. $\underline{15}$

In this incident, the shift safety officer 'responded on the working fire dispatch per fire department procedures. The shift safety officer wore an orange fire helmet that had a blue shield marked "Safety Officer" and blue colored reflective tetrahedrons around the crown of the helmet. The helmet was also labeled "SO2" on the back. He did not wear any type of reflective vest.

It should also be noted that the blue colored tetrahedrons around the crown of the fire helmet worn by the shift safety officer did not meet the helmet visibility marking requirements of NFPA 1971 Standard on Protective Ensembles for Structural Fire Fighting and Proximity Fire Fighting (2013 edition). NFPA 1971, Section 7.5.9 states that helmet visibility markings shall be tested for retroreflectivity and fluorescence as specified in Section $8.45 \ldots$ and shall have the color be fluorescent yellow-green, fluorescent orange-red, or fluorescent red. $\underline{2}$

Recommendation \#15: Fire departments and city building departments should work together to identify and mark buildings that present hazards to fire fighters and the public.

Discussion: Abandoned buildings can and do pose numerous hazards to fire fighters' health and safety as well as the general public. $\underline{23}$ Hazards should be identified and warning placards affixed to entrance doorways or other openings to warn fire fighters of the potential dangers. Such hazards can be structural as the result of building deterioration or damage from previous fires. Gutted interiors also increase the amount of exposed flammable materials and contain open pathways for rapid flame spread. Structural hazards can occur when building owners or salvage workers remove components of the building such as supporting walls, doors, railings, windows, electric wiring, utility pipes, etc. 


\section{Shift Safety Officer Falls through Hole in Floor into Basement of Vacant Row House and Dies from Smoke Inhalation - Maryland}

Abandoned materials such as wood, paper, and flammable or hazardous substances, as well as collapse hazards, constitute additional dangers fire fighters may encounter. Collapse hazards can include chimney tops, parapet walls, slate and tile roof shingles, metal and wood fire escapes, HVAC or other mechanical equipment, solar electrical collectors and cells, advertising signs, and entrance canopies. A warning placard may be a 12-inch-square piece of metal painted reflective yellow so that it reflects light in the dark and indicates to fire fighters that hazards exist inside the building. Figure 1 illustrates symbols used on warning placards developed and used by the New York City Fire Department (FDNY). $\underline{24}$ Note: The checkbox with one slash indicates the building is vacant and there are interior hazards that fire fighters need to be aware of. The checkbox with an $X$ in it indicates the building is seriously compromised and fire fighters should not enter, but rather initiate an exterior attack.

Fire departments should work with city and local authorities to develop and implement a strategy to identify, mark, secure, and where possible demolish unsafe structures within their jurisdictions. The IAAI / USFA Abandoned Building Project, conducted by the International Association of Arson Investigators and the US Fire Administration, is one example of a program that can be utilized to aid and assist fire fighter safety and health by identifying, marking, and removing unsafe structures. $\underline{23}$ The Abandoned Building Project Toolbox can be found at the Web site: http://www.interfire.org/fea-

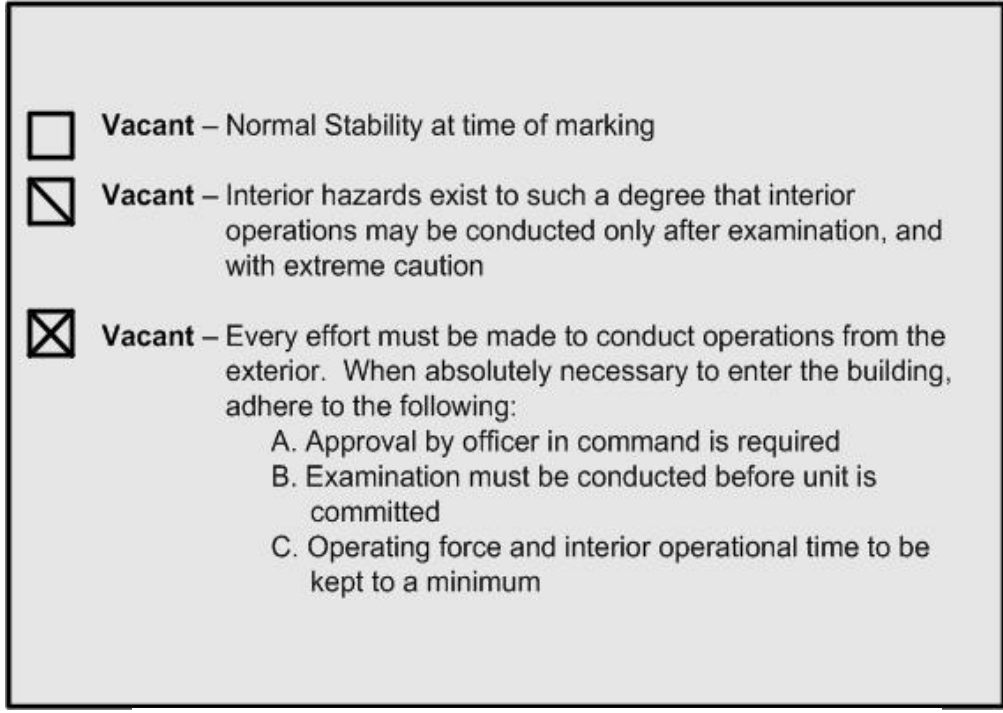

Figure 1. Warning placard used by FDNY to identify hazards in vacant buildings tures/AbandonedBuildingProjectToolBox.asp.

The toolbox contains the Abandoned Building Project report Managing Vacant and Abandoned Properties in Your Community and other reference materials. This report includes recommendations on how fire departments can work with governmental authorities to reduce the public safety hazard created by unsafe and abandoned buildings. A number of locations across the country have developed laws and regulations that address the public safety hazards created by vacant and abandoned buildings. Examples are the Commonwealth of Massachusetts, Abandoned or Dangerous Building Regulations 780 CMR and $527 C M R \underline{25}$ and the City of Cincinnati Vacated Building Maintenance License. $\underline{26}$ The NFPA 1 Fire Code, Annex Q Fire Fighter Safety Building Marking System makes direct reference to the potential resolution to identifying hazardous structures and contents through building marking programs. $\underline{27}$

This incident occurred in a city block containing a mixture of both inhabited and vacant row houses. Some of the vacant row houses had been abandoned and were in various states of disrepair. The row 


\section{Shift Safety Officer Falls through Hole in Floor into Basement of Vacant Row House and Dies from Smoke Inhalation - Maryland}

house where the shift safety officer was found had a large opening in the floor at the rear of the first floor. Some time prior to this event, a large portion of the floor at the rear of the building had been removed. If this hazard had been identified by a building marking program, a different outcome might have occurred.

\section{References}

1. Wikipedia [2015]. Row House. http://en.wikipedia.org/wiki/Terraced_house. Date accessed: March 6, 2015.

2. NFPA [2013]. NFPA 1971 Standard on Protective Ensembles for Structural Fire Fighting and Proximity Fire Fighting, 2013 ed. Quincy, MA: National Fire Protection Association.

3. Weather Underground [2014]. Weather conditions for November 12, 2014. http://www.wunderground.com/history/airport/KBWI/2014/11/12/DailyHistory.html?req_city= NA\&req_state=NA\&req_statename=NA . Date accessed: December 16, 2014.

4. Merriam-Webster [2014]. Merriam-Webster online dictionary: weather inversion. http://www.merriam-webster.com/dictionary/temperature\%20inversion . Date accessed: December 16, 2014.

5. NFPA [2013]. NFPA 1561 Standard on Emergency Services Incident Management System, 2013 ed. Quincy, MA: National Fire Protection Association.

6. NFPA [2013]. NFPA 1500 Standard on Fire Department Occupational Safety and Health Program, 2013 ed. Quincy, MA: National Fire Protection Association.

7. IFSTA [2008]. Essentials of fire fighting, 5th ed. Oklahoma State University. Stillwater, OK: Fire Protection Publications, International Fire Service Training Association.

8. Brennan, C. [2009]. Fire Service Warrior: Situational awareness. November 3, 2009. http://thefireservicewarrior.blogspot.com/2009/11/situational-awareness.html . Date accessed, April 2015.

9. Gasaway, R.B. [2013]. Situational Awareness for Emergency Response. Tulsa, OK: PennWell.

10. IAFC [2012]. Rules of engagement for structural firefighting. Fairfax VA: International Association of Fire Chiefs, Safety, Health and Survival Section. http://websites.firecompanies.com/iafcsafety/files/2013/10/Rules_of_Engagement_short_v10_2 .12.pdf]. Date accessed: March 2015. 


\section{Shift Safety Officer Falls through Hole in Floor into Basement of Vacant Row House and Dies from Smoke Inhalation - Maryland}

11. National Fallen Firefighters Foundations [2004]. 16 Life Safety Initiatives. http://www.everyonegoeshome.com/16-initiatives/4-empowerment/ . Date accessed: April 2015.

12. NFPA [2013]. NFPA 1982 Standard on Personal Alert Safety Systems, 2013 ed. Quincy, MA: National Fire Protection Association.

13. Ciarrocca M \& Harms T [2011]. Help on the scene. FireRescue Magazine. February 2011, vol 29, issue 2. Pp 40-48.

14. OSHA [1998]. 29 CFR Parts 1910 and 1926 Respiratory Protection; Final Rule. Federal Register Notice 1218-AA05. Vol. 63, No. 5. January 8, 1998. U.S. Department of Labor, Occupational Safety and Health Administration. Washington DC.

15. Dodson D. [2007]. Fire Department Incident Safety Officer, $2^{\text {nd }}$ Edition. Clifton Park, NY. Thomson Delmar Learning.

16. IAFF. IAFF Fire Ground Survival Program. Washington, DC: International Association of Fire Fighters [http://www.iaff.org/HS/FGS/FGSIndex.htm]. Date accessed: April 2014.

17. Clark, BA [2005]. 500 Maydays called in rookie school. Firehouse.com. http://www.firehouse.com/topic/strategy-and-tactics/500-maydays-called-rookie-school . Date accessed: July 2015.

18. Grossman D, Christensen L [2008)]. On combat: the psychology and physiology of deadly conflict in war and peace, 3rd ed. Millstadt, IL: Warrior Science Publications.

19. NFPA [2013]. NFPA 1001 standard for fire fighter professional qualifications. 2013 ed. Quincy, MA: National Fire Protection Association.

20. Clark BA [2008]. Leadership on the line: Firefighter Mayday doctrine where are we now? Firehouse.com. http://www.firehouse.com/podcast/leadership-line/leadership-line-firefightermayday-doctrine-where-are-we-now. Date accessed: July 2, 2015.

21. U.S. Fire Administration [2006]. Mayday CD Q133 Firefighter safety: calling the Mayday and H134 Calling the Mayday: hands on training. Emmitsburg, MD: U.S. Department of Homeland Security, U.S. Fire Administration, National Fire Academy.

22. NFFF [2014]. Vulnerability Assessment Program. National Fallen Firefighters Foundations. https://www.firevap.org/system/overview . Date accessed: July 2, 2015.

23. IAAI / USFA [2006]. Abandoned Buildings Project: Managing Vacant and Abandoned Properties in your Community. 2006 revision. International Association of Arson 


\section{Shift Safety Officer Falls through Hole in Floor into Basement of Vacant Row House and Dies from Smoke Inhalation - Maryland}

Investigators / U.S. Fire Administration joint report.

http://www.interfire.org/features/pdfs/Background\%20Paper_2006.pdf . Date accessed: July 2, 2015.

24. NIOSH [2010]. NIOSH ALERT: Preventing Deaths and Injuries of Fire Fighters using Risk Management Principles at Structure Fires. July 2010. Cincinnati, OH: U.S. Department of Health and Human Services, Public Health Service, Centers for Disease Control and Prevention, National Institute for Occupational Safety and Health (NIOSH), Publication No. 2010-153. http://www.cdc.gov/niosh/docs/2010-153/ .

25. Commonwealth of Massachusetts [2008]. Abandoned or Dangerous Building Regulations 780 CMR and 527 CMR. Commonwealth of Massachusetts, Executive Office of Public Safety and Security. Memorandum to all Heads of Fire Departments. February 1, 2008. http://www.mass.gov/eopss/agencies/dfs/dfs2/osfm/fire-prev/advisories/2000/abandonedbuildings-regulations.html Date accessed: July 2, 2015.

26. City of Cincinnati [2006]. Vacant Building Maintenance License Ordinance. Cincinnati Municipal Code 1101-77. March 2006. http://www.cincinnati-oh.gov/communitydevelopment/linkservid/2B9F59F3-CC02-4520-ACF7D7A0042FF04E/showMeta/0/ Date accessed: July 2, 2015.

27. NFPA [2009]. NFPA 1 Fire Code. 2015 ed. Quincy, MA: National Fire Protection Association.

\section{Investigator Information}

This incident was investigated by Timothy R. Merinar, Safety Engineer and Murrey Loflin, Investigator, with the Fire Fighter Fatality Investigation and Prevention Program, Surveillance and Field Investigations Branch, Division of Safety Research, NIOSH located in Morgantown, WV. An expert technical review was provided Matthew Tobia, Assistant Chief, Loudoun County Virginia Combined Fire Rescue System and David W. Dodson, Response Solutions, LLC. A technical review was also provided by the National Fire Protection Association, Public Fire Protection Division.

\section{Additional Information}

\section{Maryland Fire and Rescue Institute}

The Maryland Fire and Rescue Institute (MFRI) of the University of Maryland is the State's comprehensive training and education system for emergency services. The Institute plans, researches, develop, and delivers quality programs to enhance the ability of emergency services providers to protect life, the environment, and property. MFRI is the State's fire and emergency service training agency. The Institute has more than 80 years of experience in providing training to protect the citizens of Maryland. Over four hundred certified instructors serving as part-time faculty support more than fifty full-time faculty and staff members. MFRI programs rely on the knowledge and resources of the 


\section{Shift Safety Officer Falls through Hole in Floor into Basement of Vacant Row House and Dies from Smoke Inhalation - Maryland}

University of' Maryland system to obtain service and assistance to serve you. The University of Maryland is a not-for-profit governmental agency of the State of Maryland.

http://www.mfri.org/

\section{IAFC Rules of Engagement for Firefighter Survival}

The International Association of Fire Chiefs (IAFC) is committed to reducing fire fighter fatalities and injuries. As part of that effort, the nearly 1,000 - member Safety, Health and Survival Section of the IAFC has developed DRAFT "Rules of Engagement for Structural Firefighting" to provide guidance to individual fire fighters and incident commanders, regarding risk and safety issues when operating on the fireground. The intent is to provide a set of model procedures for structural fire fighting to be made available by the IAFC to fire departments as a guide for developing their own standard operating procedure.

\section{http://www.iafcsafety.org/downloads/Rules_of_Engagement}

\section{IAFF Fireground Survival Program.}

The purpose of the Fire Ground Survival program is to ensure that training for Mayday prevention and Mayday operations are consistent between all fire fighters, company officers and chief officers. Fire fighters must be trained to perform potentially life-saving actions if they become lost, disoriented, injured, low on air or trapped. Funded by the IAFF and assisted by a grant from the U.S. Department of Homeland Security (DHS) through the Assistance to Firefighters (FIRE Act) grant program, this comprehensive Fire Ground Survival training program applies the lessons learned from fire fighter fatality investigations conducted by the National Institute for Occupational Safety and Health (NIOSH) and has been developed by a committee of subject matter experts from the IAFF, the International Association of Fire Chiefs (IAFC) and NIOSH.

http://www.iaff.org/HS/FGS/FGSIndex.htm.

\section{Disclaimer}

Mention of any company or product does not constitute endorsement by the National Institute for Occupational Safety and Health (NIOSH). In addition, citations to Web sites external to NIOSH do not constitute NIOSH endorsement of the sponsoring organizations or their programs or products. Furthermore, NIOSH is not responsible for the content of these Web sites. 


\title{
Shift Safety Officer Falls through Hole in Floor into Basement of Vacant Row House and Dies from Smoke Inhalation - Maryland
}

\author{
Appendix One
}

\section{Personal Protective Equipment Evaluation}

\author{
Summary and Conclusions
}

\section{Radio Evaluation Summary}

The radio evaluation was conducted on January 6, 2015. As part of the evaluation process, the radio was first evaluated at one of the fire department's stations and then transferred to the manufacturer's testing facility for additional evaluation and testing. This evaluation consisted of testing the radio for proper programing and operation to determine if there were any faults in its operation that may have contributed to the fatality.

During this process, the radio operated properly. There weren't any faults or programming issues noted during the inspection and evaluation that would have contributed to the fire fighter fatality.

Note: Prior to the NPPTL radio evaluation, the fire department evaluated the radio's performance by operating the radio from within the Delta exposure basement on December 11, 2014 during the NIST pressure and ventilation testing. Fire department personnel radioed the Fire Communication Bureau and received acknowledgement. At that time, the radio performed as expected.

\section{Helmet Evaluation Summary}

The helmet worn by the shift safety officer was less than one year old and in very good condition. NIOSH investigators observed a scuff mark and stress crack in the helmet's outer shell to the left of the helmet emblem. A quantity of what appeared to be dried blood was observed on the outer shell. The scuff mark and stress crack in the helmet suggest a glancing impact from the fall. The disposition of the suspension system is consistent with a directional force suffered during the fall. The interior impact cap showed no signs of damage from a direct or glancing impact. See Photo 6 and Appendix One for more information.

The helmet involved in this incident, while structurally identical to the NFPA version of the helmet, only met the requirements of OSHA US-OSHA Standard 29 CFR 1910.156. This helmet did not meet the minimum visibility and color requirements specified in the National Fire Protection Association (NFPA) 1971 Standard on Protective Ensembles for Structural Fire Fighting and Proximity Fire Fighting (2013 Edition). $\underline{2}$

To meet the NFPA visibility requirements, the helmet visibility markings must be both retro-reflective and fluorescent (Section 6.5.3). The approved colors are fluorescent lime-yellow, fluorescent redorange and fluorescent red (Section 7.5.9). The tetrahedrons on the helmet involved in this incident were blue and thus did not meet the color requirements of NFPA Section 7.5.9. To meet the eye and face protection requirements of NFPA 1971 the helmet must be equipped with either goggles or a 


\section{Shift Safety Officer Falls through Hole in Floor into Basement of Vacant Row House and Dies from Smoke Inhalation - Maryland}

faceshield. This helmet was equipped with flip down eye shields that do not meet the requirements for NFPA Section 6.4.5. The helmet did not contain an NFPA approval label.

There are many factors that are needed to calculate an accurate force generated during a fall from a certain height. In this case we must estimate the circumstances involving the speed, deceleration, impact of the body, and their relation to the incident.

Estimated Height of First Floor from Basement Floor - 7 Feet (see Photo 4)

Estimated Height of Fire Fighter- 6 Feet

Estimated Weight of Shift Safety Officer - 230 pounds

Estimated Stopping Distance (deceleration) - 1/2 foot (0.5)

Estimated Force from Fall- In excess of 6,200 pounds

Based on the inspection, the protective helmet performed as intended for the event and it is not believed to have contributed to the fatality of this incident.

The complete NPPTL evaluation reports covering the radio and helmet are available upon request 